\title{
Water vapour condensation in a partly closed structure. Comparison between results obtained with an inside wet or dry bottom wall
}

\author{
Jean Batina ${ }^{1} \cdot$ René Peyrous ${ }^{2}$
}

\begin{abstract}
We are interested in the determination of the more significant parameters acting on the water vapour condensation in a partly closed structure, submitted to external constraints (temperature and humidity), in view to recover the generated droplets as an additional source of potable water. External temperature variations, by inducing temperature differences between outside and inside of the structure, lead to convective movements and thermal variations inside this structure. Through an orifice, these movements permit a renewing of the humid inner air and can lead to the condensation of the water vapour initially contained in the inner air volume and/or on the walls. With the above hypotheses, and by using a numerical simulation [1] based on the ambient air characteristics and a finite volumes method, it appears that condensed water quantities are mainly depending on the boundary conditions imposed. These conditions are: 1) dimensions of the structure; 2) external temperature and relative hygrometry; 3 ) the phase $\varphi(\mathrm{T} / \mathrm{RH})$ linking thermal and hydrometric conditions; 4$)$ the air renewing and its hygrometry for each phase; and 5) for each case, the fact that the inside bottom wall can be wet or dry. The resulting condensed water vapour quantities obtained, for the width section, point out clearly that they are very depending on this phase $\varphi(T / R H)$ which appears as the more significant parameter and can be modified by the presence or not of a thin layer of water vapour on the inside bottom wall. Condensation phenomenon could be increased if $\varphi$ could be optimized.
\end{abstract}

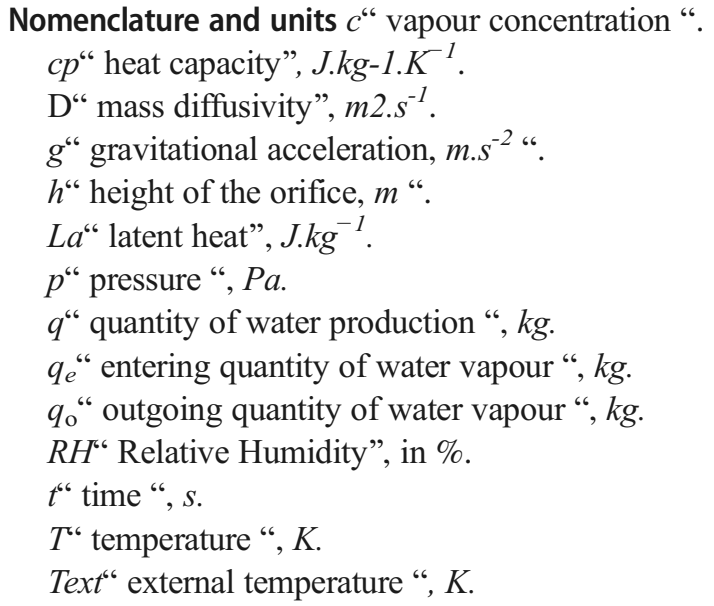

Jean Batina jean.batina@univ-pau.fr

1 Laboratoire des Sciences de l'Ingénieur Appliquées à la Mécanique et à l'Électricité (SIAME), Université de Pau et des Pays de l'Adour, BP1155, 64013 Pau, France

2 Laboratoire d'Electronique des Gaz et des Plasmas, Université de Pau et des Pays de l'Adour, 64000 Pau, France

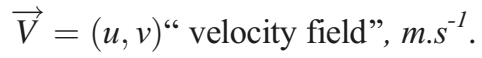

Greek symbols $\delta \mathrm{T}^{\text {“ }}$ temperature difference from $15^{\circ} \mathrm{C}(0$ initial value) ", $K$.

$\varphi$ “ phase between T and RH ".

$\rho$ "volume mass", $\mathrm{kg} \cdot \mathrm{m}^{-3}$.

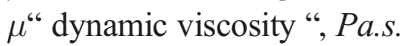

$\lambda$ " thermal conductivity", $W \cdot m^{-1} \cdot K^{-1}$.

$\eta "$ condensed water ratio ", $\%$.

$\Omega$ “ study domain ".

\section{Introduction}

Water resources is become a present problem and its possible solution could be the recovery of the dew or of the water vapour contained in ambient air by using condensation. This subject was yet the aim of a lot of experimental and fundamental works which have shown this possibility. The basic physical phenomena of the dew formation and the possibility to improve its recovering have been firstly studied, among others, by R. V. Wahlgren [2], Nikolayev et al. [3]. In the same way, and following the dew harvesting attempts made by Chaptal and Knappen in France (1930) and the Zibold's one in Feodosia in Ukrainia 
(1907), various dew water collectors for potable water were developed in Ajaccio by Muselli et al. [4] and Beysens et al. by using essentially radiative cooling process $[5,6]$. In their researches concerning the mechanism of soil water vapour adsorption in arid regions, Beysens et al. [7] concluded that "there are areas in which, during the dry season, the dominant process is vapour adsorption, and dew formation is a rare occurrence.". Importance of the characterisation of the main parameters occurring in the formation of water vapour condensation, particularly in arid regions, was pointed out by all these studies and several others on the same subject.

Various numerical simulation where used to describe, understand, and explain this complex process in which heat and mass transfer and thermodynamic of the mixture occur in a strong interactive manner at the same time (Clus et al. [8], I. Lekouch [9], Gandhidasan and Abualhamayel [10], Beysens et al. [11], Caltagirone and Breil. [12]).

But successes concerning water recovering possibilities by mean of water vapour contained in ambient air remain limited and this topic causes a lot of scientific debates mainly dealing with its economic interest (Ben Gido et al. [13]).

The goal of our work is attempting to define the more significant parameters acting on the conditions of the water vapour condensation present in air, inside a closed or partly closed structure (Batina et al. [14, 15]). An illustration of such phenomena was yet observed in the nonwatertight sarcophagus of Arles-sur-Tech (France) (Beysens et al. [16], Perard and Leborgne [17]). This marble walls structure, of an about $0.33 \mathrm{~m}^{3}$ internal volume, is submitted to external atmospheric conditions (temperature and humidity). These latter generate locally convective movements and thermal variations inside this space and can induce, inside the volume or/and on the walls, water vapour condensation of the air initially contained in the structure or renewed through an orifice.

Our study is essentially based on this Arles-sur-Tech sarcophagus example, for which we have some experimental results running on some months (in fact between 1997 and 2000). Despite their importance, the dimensions and the volume of the structure, the dimension of the orifice, and the nature of the walls material (marble) remain unchanged in this study.

At first, and in a simplified way, approach of the external atmospheric constraints (temperature and hygrometry) was approximated by representing the daily thermal variations (Text) by a sinusoidal function and the relative hygrometry variations $(\mathrm{RH})$ by crenels with a same period. These two parameters are linked by a temporal phase $\varphi(\mathrm{T} / \mathrm{RH})$ which can be modified by steps of $3 \mathrm{~h}$, from $0 \mathrm{~h}$ (midnight) to $24 \mathrm{~h}$.

Thermal and hydrometric evolutions and the resulting condensed water quantities, inside the considered volume, are represented, for a transverse section, at various moments of the day as a function of the phase $\varphi(\mathrm{T} / \mathrm{RH})$ for $\varphi=0 \mathrm{~h}$ and $\varphi=12 \mathrm{~h}$. This study, as a function of $\varphi$, on the dynamical and thermal behaviour and on the condensation effects, shows the existence of an optimum of condensation linked with this parameter $\varphi([1,14,15])$.

\section{Modelling}

\subsection{Equations}

The study domain (Figs. 1) is a parallelepipedal structure of internal dimensions $0.47 \mathrm{~m} \times 0.40 \mathrm{~m} \times 1.76 \mathrm{~m}$. corresponding to the Sarcophagus' ones. The frontal side (1) and the top side (2) are submitted to the external atmospheric conditions (temperature and humidity) varying periodically in time, when all the other sides $(3,4)$ are considered as adiabatic (null thermal flux conditions). The marble walls (6), of $0.1 \mathrm{~m}$ thick, are assumed as nonporous and smooth. This sarcophagus being not totally watertight, the "slits between the lid and the body" [16] are represented by an orifice (7). Through this orifice, situated on the upper and right part of the width section, on the frontal side of the walls submitted to the constraints, the inside air can be renewed. This renewing is only due to the outside-inside thermal gradient in an assumed absence of wind. The orifice height $h$ can be varied from $0.02 \mathrm{~m}$ up to $0.30 \mathrm{~m}$.

Only the transverse section $(0.47 \mathrm{~m} \times 0.40 \mathrm{~m})$, named "width section", in which convective movements take place, is considered (Fig. 1). Then, we assume that this problem is in two dimensions.

This problem is modelized by using a structured grid of $5940(66 \times 90)$ meshes applied to the totality of the studied domain. This grid is strongly refined in the orifice wake and in the vicinity of the walls. (Fig. 1b).

Starting from an initial configuration (initial conditions), we vary in time the thermal and hydrometric external air variables (boundary conditions on the constrained walls), with a period of $24 \mathrm{~h}$ :

- $\quad$ sinusoidal variations of the temperature (Text $=15 \pm$ $\left.5^{\circ} \mathrm{C}\right), 15^{\circ} \mathrm{C}$ at $6 \mathrm{~h}(\mathrm{am})$, maximum $\left(20^{\circ} \mathrm{C}\right)$ at $12 \mathrm{~h}$ (noon), and minimum $\left(10^{\circ} \mathrm{C}\right)$ at $24 \mathrm{~h}$ (midnight). The same thermal constraint is applied over the two adjacent external sides (faces 1 and 2), the other sides remaining adiabatic.

- crenelled periodical variations for the relative hygrometry: $\mathrm{RH}=60 \%$ during $10 \mathrm{~h} ; \mathrm{RH}=90 \%$ during $14 \mathrm{~h}$.

Despite the fact that these crenelled variations of $\mathrm{RH}$ are not realistic, nevertheless, they permitted us to check the stability of the numerical model.

At the starting moment $t=6 \mathrm{~h}$ (am), we assume that the fluid (wet air), inside the considered volume, is in a steady state with a uniform mean relative humidity and temperature.

Starting at $6 \mathrm{~h}$ (a.m.), the external air, without initial speed at the level of the orifice, is at the initial temperature of $15^{\circ} \mathrm{C}$, 


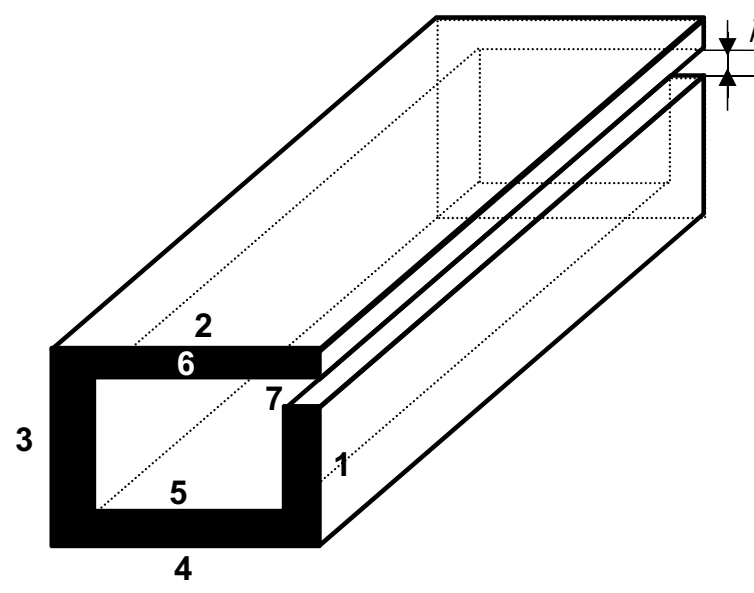

(a)

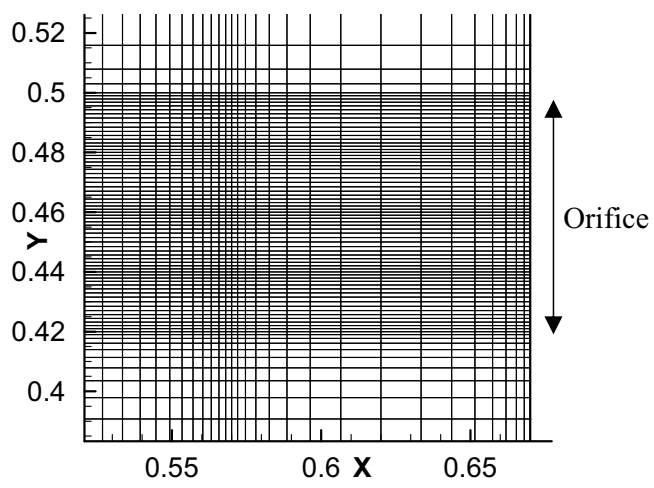

(c)

Fig. 1 a Transverse section showing the boundary conditions. Faces 1 and 2: walls submitted to periodic external constraints; faces 3 and 4: adiabatic walls; Face 5: Inside bottom of the cavity; 6: Marble thick; 7:

which can vary from 10 to $20^{\circ} \mathrm{C}$, with a relative hygrometry in a $60 \%$ to $90 \%$ range.

The humid air contained in the structure is consequently submitted to a natural convective phenomenon and its renewing is only obtained by the mean of the orifice, assumed to be $0,08 \mathrm{~m}$ height.

Atmospheric pressure, relative humidity, and temperatures involved are issued from mean values coming from the experimental results obtained by Beysens et al. [16] and Perard and Leborgne [17].

Moreover, because of the small temperature variations, we assume the Boussinesq approximation. In these conditions, the problem is described by Navier-Stokes and Energy equations (movement quantity, energy conservation and continuity equation).

Their classical vector forms are the following:

$$
\begin{aligned}
\rho\left[\frac{\partial \vec{V}}{\partial t}+(\vec{V} \cdot \vec{\nabla}) \vec{V}\right]= & -\vec{\nabla} p+\mu \vec{\nabla} \cdot\left(\Delta \vec{V}+\nabla^{t} \vec{V}\right) \\
& +\rho \vec{g}
\end{aligned}
$$

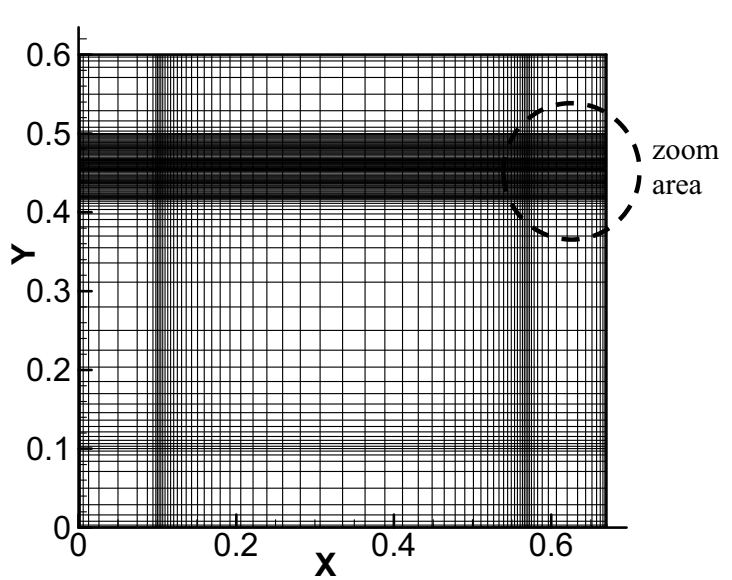

(b)

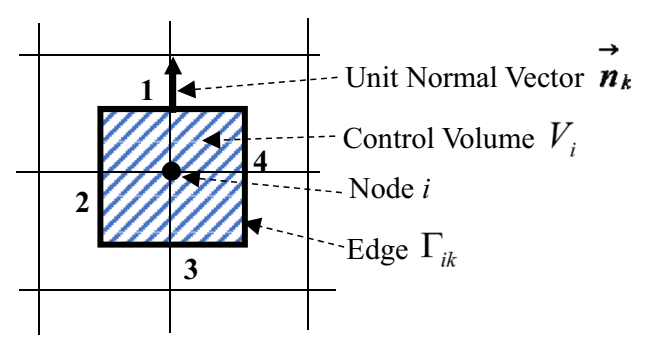

(d)

orifice. b: Mesh Grid of the study domain $\Omega ; \mathbf{1 c}$ : zoom around the orifice area; 1d: Control Volume centred on a node $i$.of the mesh grid

$\vec{\nabla} \cdot \vec{V}=0$

$\rho c_{p}\left[\frac{\partial T}{\partial t}+\vec{V} \cdot \overrightarrow{\nabla T}\right]=\lambda \Delta T+S$

To describe the water vapour variations, we introduce the Transport equation as follows:

$\frac{\partial c}{\partial t}+\vec{V} \cdot \vec{\nabla} c=\vec{\nabla}(D \vec{\nabla} c)+S^{\prime}$

where $S$ and $\mathrm{S}^{\prime}$, respectively, represent the source terms (heat for (3), and mass for (4)), coming from the external air, and representing the balance between evaporation and condensation of the water vapour contained in air. The function c represents the vapour concentration, that is in fact the Absolute Hygrometry $A H$.

The thermal and the water quantities exchanged between the outside and the inside of the sarcophagus are sufficiently small to justify the absence of the source terms in the Energy and Transport equations. Therefore, we have:

$S=S^{\prime}=0$ 


\subsection{Numerical methods}

Dynamic, Energy and Transport equations are numerically solved by a finite volumes method (Caltagirone and Breil [12]). We recall below the main principles of this wellknown method. For the sake of simplicity, we consider only the Transport equation. The other equations can be solved in the same manner. Here are the main steps of this method:

a) The Transport eq. (4) is first written in its conservative form:

$\frac{\partial c}{\partial t}+\vec{\nabla} \cdot(c \vec{V}-D \vec{\nabla} c)=0$

b) Then, we define control volumes $V_{i}$ (Fig. 1.c), centred on each node $i$ of the cartesian mesh grid of the study domain $\Omega$ (Fig. 1d), such as:

$\Omega=\cup_{i=1}^{N} V_{i}$

Where $N$ is the number of nodes in the whole domain $\Omega$. The unknowns are the values of the concentration $c$ on each node $i$

c) We write the balance equation for the convective and the diffusive fluxes on each control volume $V_{i}$ :

$\frac{\partial}{\partial t} \int_{V_{i}} c d V_{i}+\int_{V_{i}} \vec{\nabla} \cdot(c \vec{V}-D \vec{\nabla} c) d V_{i}=0$

d) Using the divergence formula, these integrals are written according to the fluxes through the four edges $\Gamma_{i k}$ of $V_{i}(1 \leq k \leq 4)$. So, we have:

$\frac{\partial}{\partial t} \int_{V_{i}} c d V_{i}+\sum_{k=1}^{4} \int_{\Gamma_{i k}}(c \vec{V}-D \vec{\nabla} c) \cdot \vec{n}_{k} d \Gamma=0$

Quadrature formulas for numerical integration are used to compute these fluxes according to the mean value of the concentration $c$ at the node $i$ :

$c_{i}=\frac{1}{\left|V_{i}\right|} \int_{V_{i}} c d V_{i}$

where $\left|V_{i}\right|$ represents the area of $V_{i}$.

At last, the obtained equations must be integrated in time. For this, several schemes of first or second orders can be used (Delage Santacreu S., [18]): UPWIND (very diffusive scheme, but who avoids numerical oscillations),
Lax-Wendroff, WENO (Weighted Essentially NonOscillatory), TVD (Total Variation Diminishing), etc. In this study, Gear scheme of second order is used. This scheme does not require the CFL (Courant-FriedrichLevy) condition between the time step and the space step to assume the stability of numerical solutions (See [18] for more details). In this study, the time-step is fixed at $5 \mathrm{~s}$.

We specify that this study does not aim to validate the numerical methods we used. Indeed, several tests of this CFD code in 1D, 2D or 3D geometries allowed to validate this finite volume method [18]. For example, we can mention essentially classical test cases, but also more complicated cases, such as: Driven Cavity, Phase Change Problems in Natural Convection, Flow in Porous Media, Dam Break Studies, Green-Taylor whirlwind, etc.

\subsection{Basic concepts of humid air}

To complete the above analysis, we need the state equations of the humid air, used in the Mollier diagram, which enable us to relate dry temperature and relative humidity with the other characteristic variables of the humid air: more particularly absolute (or specific) humidity and dew-point temperature. We resume below the basic concepts of humid air (Devres Y.O., [19]).

Humid air can be considered as a mixture of dry air $(d a)$ and water vapour (vap). The molar mass of dry air and water vapour are given respectively by:

$M_{d a}=0.028964 \mathrm{~kg} / \mathrm{mol} ; M_{\text {vap }}=0.0180153 \mathrm{~kg} / \mathrm{mol}$

The pressure of the humid air is the sum of the partial pressures of the dry air and the water vapour:

$P=P_{d a}+P_{\text {vap }}$

According to the ideal gas law, the partial pressure of dry air and the partial pressure of water vapour in humid air are respectively given by:

$P_{d a}=\frac{\rho_{d a}}{M_{d a}} R T ; P_{v a p}=\frac{\rho_{v a p}}{M_{v a p}} R T$

where $P_{d a}$ (resp. $\rho_{v a p}$ ) is the partial density of dry air (resp. water vapour), and $R$ the gas constant:

$R=(8.31441 \pm 0.00026) J . \mathrm{mol}^{-1} K^{-1}$

The total mass of the humid air in a volume $V$ is the sum of the dry air mass and the water vapour mass:

$m=m_{d a}+m_{v a p}=m_{d a}\left(1+\frac{m_{v a p}}{m_{d a}}\right)$ 
The ratio between the mass of the water vapour and the mass of dry air represents the Absolute Humidity:

$A H=\frac{m_{v a p}}{m_{d a}}\left(\right.$ given in $\left.\frac{k g_{v a p}}{k g_{a s}}\right)$

A simple calculation shows that:

$A H=\frac{M_{v a p} p_{v a p}}{M_{d a} p_{d a}}=0.6219894 \frac{p_{v a p}}{p_{d a}}=0.6219894 \frac{p_{v a p}}{p-p_{v a p}}$

The relative Humidity $R H$ is defined by:

$R H=\frac{p_{\text {vap }}}{p_{\text {sat }}(T)}$

where $p_{\text {sat }}(T)$ represents the saturated vapour pressure at a temperature of $T(R H=1$, or $100 \%$, the air is completely saturated). Using the equilibrium between water and humid air, one can prove the following law of humid air:

$\log _{10}\left(p_{\text {sat }}\right)=\frac{7.625 T}{(241+T)}+2.7877$ with $p_{\text {sat }}$ expressed in $P a$, and $T$ in ${ }^{\circ} C$

Moreover, because of low velocities involved, we assume that the total pressure $p$ is everywhere close to the ambient atmospheric pressure:

$p \approx 101325 P a$

At each time $t$, the temperature $T$ and the Absolute Humidity $A H$ are obtained by solving the dynamic, thermal and Transport eqs. (1) to (4), according to initial and boundary conditions described above.

The dew point temperature $T_{\text {dew }}$ is the temperature of the saturated vapour at which it has the same vapour pressure as the ambient humid air, that is when we maintain $A H$ constant. Because $R H=1$ in this case, $T_{\text {dew }}$ can be easily deduced using relations (18) and (19).

Finally, according to the relations (11) to (20), we can deduce one of the 3 variables $T, R H, A H$ as a function of the 2 others. The Mollier diagram is built using these relations. Note that these laws are available with a good accuracy.

\subsection{Initial and boundary conditions}

The study domain includes the marble and the interior of the cavity. The marble is considered as an obstacle for the dynamic problem.
We consider that the water production and the thin layer of humid air imposed at the bottom wall of the inside cavity are sufficiently small to assume that the inside geometry and the boundary conditions imposed on the walls are not modified by the presence of this thin film. Indeed, if the exchanged water quantities between the outside and the inside of the cavity had been strongly significant, it should be necessary to consider both a transformed geometry and some modified boundary conditions at each time step of the numerical computation. Our problem is out of this situation.

At each instant $t$, boundary conditions can be summarized as follows:

\section{- Initial conditions $(t=0)$}

As initial conditions, we suppose that there is no flow in all the study domain, the temperature and humidity conditions inside the cavity are equal to those imposed outside.

\section{- Unsteady flow $(t>0)$}

As we can see in the Fig. 1.a:

Faces 1 and 2: Top and right boundaries

- Dynamic conditions: $u=v=0$, as on all solid boundaries

- Thermal conditions: external sinusoidal temperature imposed

- Water vapour conditions: identical to those imposed in the marble

Face 3 and 4: Left and bottom boundaries

- Dynamic conditions: $u=v=0$, as on all solid boundaries

- Thermal conditions: adiabatic conditions $\frac{\partial T}{\partial x}=0$

- Water vapour conditions: identical to those imposed in the marble

Face 5: Inside bottom of the cavity

- Initially dry in a first time [1], only a thin layer saturated water vapour is imposed in this study.

Marble 6: All functions are null in the marble, except the temperature $T$.

Orifice 7:

- Dynamic conditions: the flow velocity is normal to the entry section (absence of an imposed external wind velocity) and verifies the classical free entry conditions $v=\frac{\partial u}{\partial x}=0$ 
- Thermal conditions: the same sinusoidal temperature as for 1 and 2

- Water vapour conditions: a creneled water vapour function is imposed

\subsection{Calculation procedure}

At each time step $t$, using Finite Volume Method summarised above, the velocity field $\vec{V}$, the temperature $T$, and the Absolute Humidity $A H=c$ are obtained by solving the Dynamic, Thermal and Transport eqs. (1) to (4), according to the initial and boundary conditions described above.

To calculate water production $q(t)$, which can be considered as a post-treatment, we proceed as follows:

- In each Control Volume $V_{i}$ :

- Using the humid air laws (11) to (20), we deduce the Relative Humidity $R H$ and the dew temperature $T_{d e w}$.

- If $R H<1$, there is no condensation in the considered Control Volume. The local water production $q_{i}(t)$ in this cell is null: $q_{i}(t)=0$. Then we analyse the next Control Volume.

- If $R H=1$, the water vapour is saturated in the present Control Volume. Local water production $q_{i}(t)$ in this cell is not null: $q_{i}(t) \neq 0$. Its value is calculated using $A H$. The next Control Volume is analysed.

The global water production $q(t)$ in the whole study domain $\Omega$, at the time $t$, is the sum of local water productions in each Control Volume $V_{i}$ :

$q(t)=\sum_{i=1}^{N} q_{i}(t)$

- $\quad$ End of the procedure.

\section{Results and discussion}

All the results previously presented (Batina and Peyrous [1]) were dealing only with the simplified hypothesis of an inside bottom wall remaining dry. Starting from these stable initial conditions, we have yet shown that the considered system reaches a steady state regime (no more variations at the same time from day to day) after 3 days (see Figs. $6 \& 7$ ). The internal air dynamic behaviours have shown that the condensation effects are a function of the phase, $\varphi$, and of the orifice height. Moreover, it appeared clearly that there is possibility to reach an optimum of condensation linked with these parameters.

Now these previous results are compared to those obtained with a wet bottom wall covered by a thin layer of saturated humid air (100\% RH) remaining level-constant in time. This thin layer represents the water "dead volume" of 2,5 1 [16] equally distributed on the inside bottom wall surface $\left(0,83 \mathrm{~m}^{2}\right)$.

This further hypothesis of a thin layer of saturated humid air remaining level-constant in time will permit to work with a constant inner volume of air.

By introducing this new hypothesis - presence of a thin layer $(3 \mathrm{~mm})$ of saturated humid air $(100 \% \mathrm{RH})$ on the inside bottom wall - we will act on the behaviour of the local temperature velocity-fields and inside $\mathrm{RH}$ distribution of the bidimensional section. Consequently, comparisons are made between two cases: the wet bottom wall and, as previously reported, the remaining dry bottom wall.

The more meaningful results obtained in a fixed configuration are only shown for the width section of the considered structure, with a $0.08 \mathrm{~m}$ orifice, for two phases $(\varphi=0 \mathrm{~h}$ and $\varphi=12 \mathrm{~h}$ ) at various moments.

In the previous paper, (Batina et al. [1]), dealing only with the results obtained in the case of an inside bottom wall remaining dry, we have presented the main role played by the thermal gradient between the outside and the inside of the structure. In the same way, the role of the thermal inertia of the walls on the fluid circulation inside the studied volume was pointed out. This inside air circulation, which depends on the considered phase $(\varphi)$, will act on the isothermal and iso-humidity distributions in the structure.

\subsection{Phase $\varphi=0 \mathrm{~h}$}

In our initial phase $\varphi(\mathrm{T} / \mathrm{RH})=0 \mathrm{~h}$ (Fig. 2) the lowest relative hygrometry $(\mathrm{RH}=60 \%)$ is centred at noon $(12 \mathrm{~h})$ starting from $7 \mathrm{~h}$ (am) up to $17 \mathrm{~h}(5 \mathrm{~h} \mathrm{pm})$, and the highest $(\mathrm{RH}=$ $90 \%)$, centred at midnight, from $17 \mathrm{~h}(5 \mathrm{~h} \mathrm{pm})$ up to $7 \mathrm{~h}(\mathrm{am})$

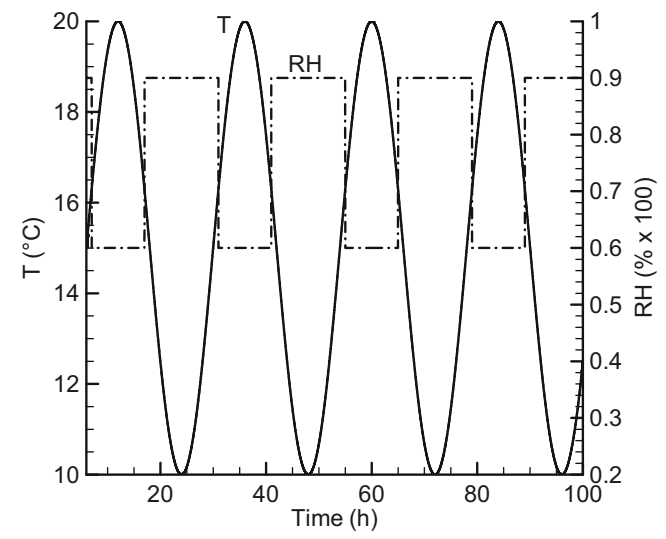

Fig. 2 Temperature (T) and relative humidity $(\mathrm{RH})$ temporal evolutions of the external air (boundary conditions on the constrained walls): phase $\boldsymbol{\varphi}=\mathbf{0}$ h. $\mathrm{T}\left({ }^{\circ} \mathrm{C}\right)=$ Text $=$ external temperature 
the next morning. This phase $\varphi$ can be modified by shifting $\mathrm{RH}$ by step of $3 \mathrm{~h}$ in time.

Differences between the two considered cases will be shown by positioning the figures corresponding to the inside wet bottom wall case at left and the ones for the dry bottom at right.

We start firstly by the iso-therms (Figs. 3) followed by the iso-humidity curves (Figs. 4) for the successive time conditions: $6 \mathrm{~h}(\mathrm{am}), 12 \mathrm{~h}$ (noon), $18 \mathrm{~h}(6 \mathrm{pm})$ and $0 \mathrm{~h}$ (midnight), in accordance with the fig. 2.

\subsubsection{Isotherms}

Figures 3 represent the isotherms which are indicative of the temperature evolution inside the marble walls and in the volume. These isotherms indicate a natural convective activity, fairly important in some occurrences, by temperature difference values of about $5^{\circ} \mathrm{C}$, able to produce condensation phenomena or "drying" effects inside the structure.
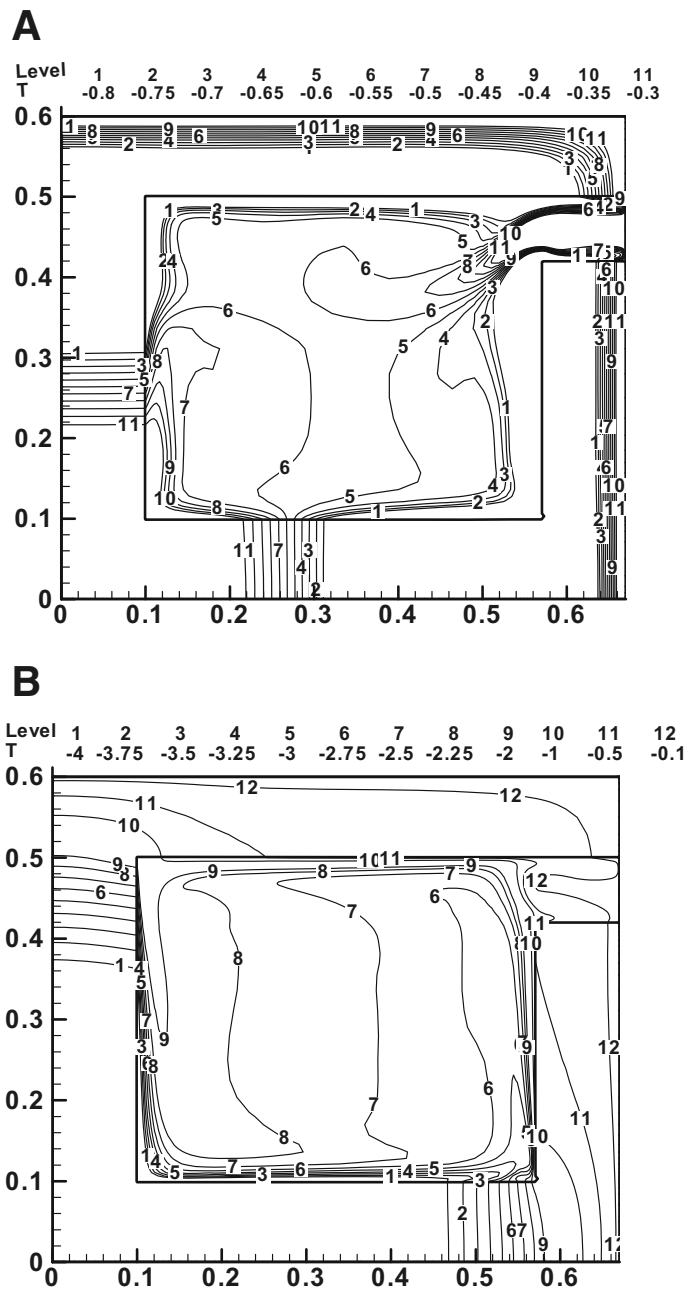

In our previous paper [1], in these figures, these temperature difference values were initially compared with $15{ }^{\circ} \mathrm{C}$ considered as reference value as used in the calculations. Now, the temperature scales (T) are compared with the external value (Text) at the considered moment to be more representative of the inner variations, in the walls and inside the volume of the structure. Consequently, for the isotherms at $6 \mathrm{~h}(\mathrm{am})$ and $18 \mathrm{~h}(6 \mathrm{pm})$, when the external temperature Text $=15{ }^{\circ} \mathrm{C}$, the previous results for the dry bottom wall are shown in the same manner as they appear in [1].

As the previous results obtained have shown, and as it can be verified on the following Figs. 5, 6 and 7, a steady-state system was obtained inside the volume considered. Consequently, comparisons were made between the results obtained for the days following the third.

Figures 3, at $\boldsymbol{t}=\mathbf{6} \mathbf{h}(\mathbf{a m})$, Text $=15^{\circ} \mathrm{C}$.

In the case of the wet inside bottom wall, inside the constrained marble walls, the isotherms distribution presents
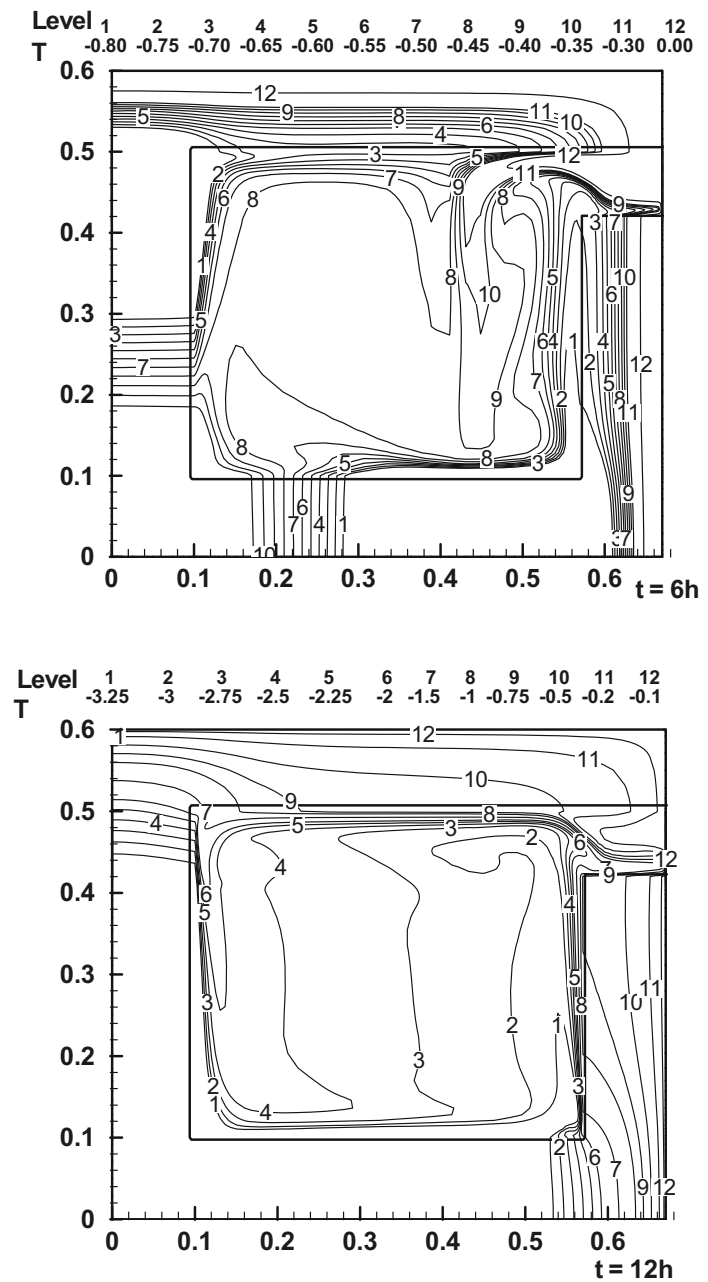

Fig. 3 a: $\boldsymbol{t}=\mathbf{6} \mathbf{~ h}(\mathbf{a m}) ; \mathbf{T e x t}=15^{\circ} \mathbf{C} ; \mathrm{RH}=90 \%$. b: $\boldsymbol{t}=\mathbf{1 2} \mathbf{~ h}$ (noon); Text $=\mathbf{2 0}{ }^{\circ} \mathbf{C} ; \mathrm{RH}=60 \%$. c: $\boldsymbol{t}=\mathbf{1 8} \mathbf{~ h} ; \mathbf{T e x t}=\mathbf{1 5}{ }^{\circ} \mathbf{C} ; \mathrm{RH}=90 \%$. d: $\boldsymbol{t}=\mathbf{0} \mathrm{h}(\mathbf{m i d n i g h t}) ;$ Text $=10{ }^{\circ} \mathrm{C} ; \mathrm{RH}=90 \%$ 
C

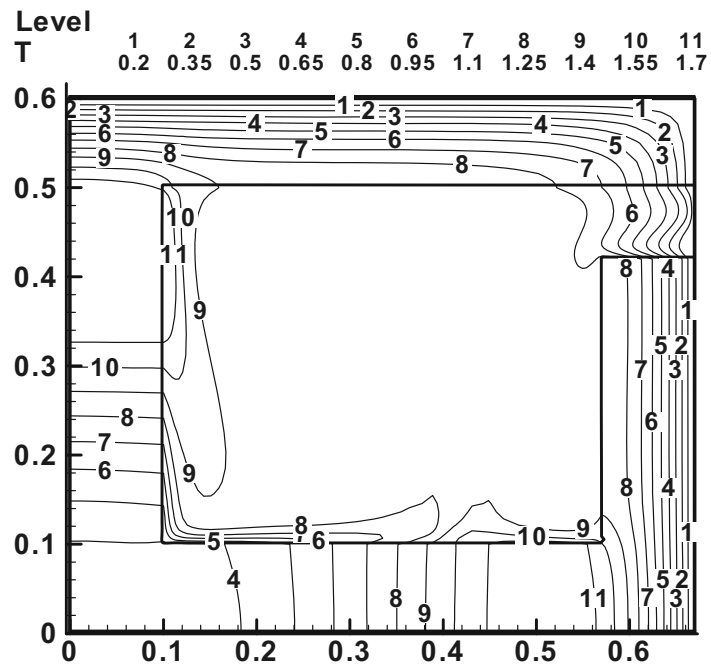

D

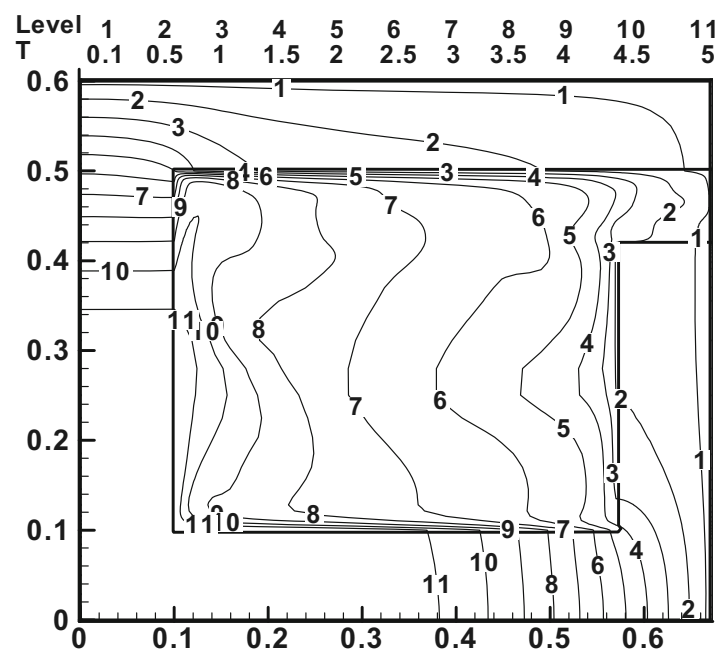

Fig. 3 (continued)

a strong gradient towards the outside, with a very rapidly decreasing temperature from the outside to the inside, when it is the reverse in the case of the dry bottom.

Inside the structure volume, for a similar thermal variation, isotherms gradients are more important near the constrained walls in the dry bottom wall case.

It appears that the thermal inertia of the constrained walls is modified in the case of the wet bottom wall.

In addition, in the case of the dry bottom, fluid velocities, with a size order of $5.10^{-2} \mathrm{~m} / \mathrm{s}$ at the orifice entrance, are mainly clock-wise, with a double cell circulation in the volume, are more important than in the wet bottom case.

As a result, due to a lower residence-time, condensation possibilities are consequently reduced. This relatively important air circulation is linked with the continuous increasing
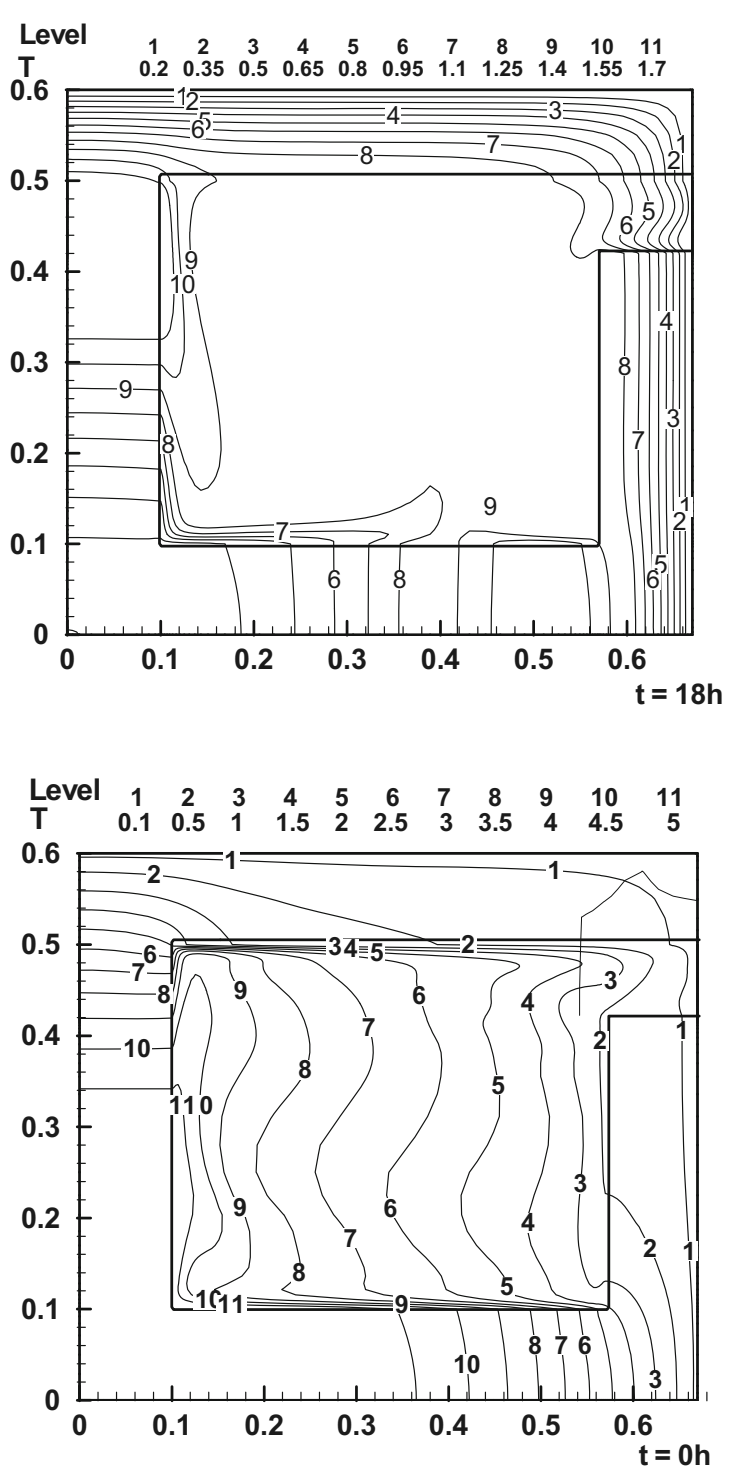

temperature since $0 \mathrm{~h}$ (midnight) up to $12 \mathrm{~h}$ (noon) and the increasing temperature difference between outside and inside, since about $5 \mathrm{~h}(\mathrm{am})$, focusing the air exchanges from the outside to the inside (see figures $6 \mathrm{a}$ ).

Figures $3 \mathrm{~b}: t=12 \mathrm{~h}$ (noon); Text $=20^{\circ} \mathrm{C}$.

It can be noted that the internal upper temperature variation compared with the external one is obtained at noon. But in the wet bottom case there is a higher difference $\left(\sim 3,4{ }^{\circ} \mathrm{C}\right)$ than in the dry bottom case $\left(\sim 3{ }^{\circ} \mathrm{C}\right)$ all along the inner walls and inside the volume. This is due to the more important temperature gradients, inside the constrained walls, in the case of the wet bottom than in the dry bottom one. That leads to a lower temperature inside the volume for the dry bottom when it is all along the walls for the wet bottom case. 


\section{A}

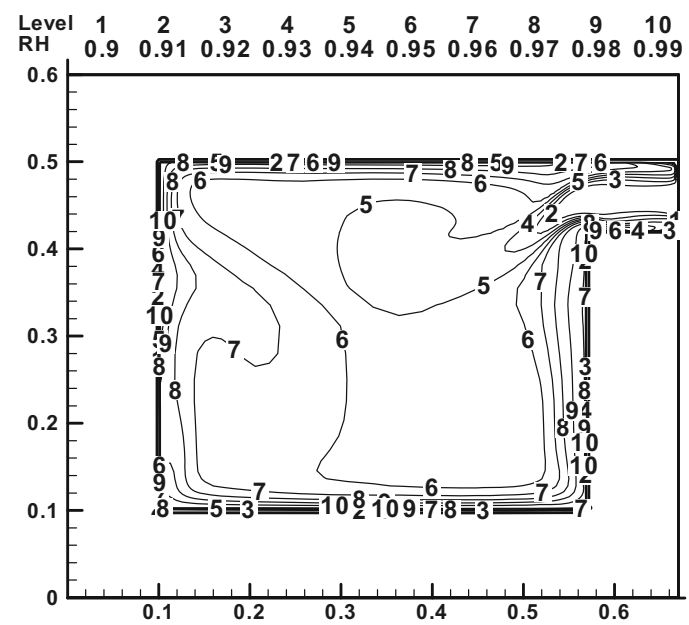

\section{B}

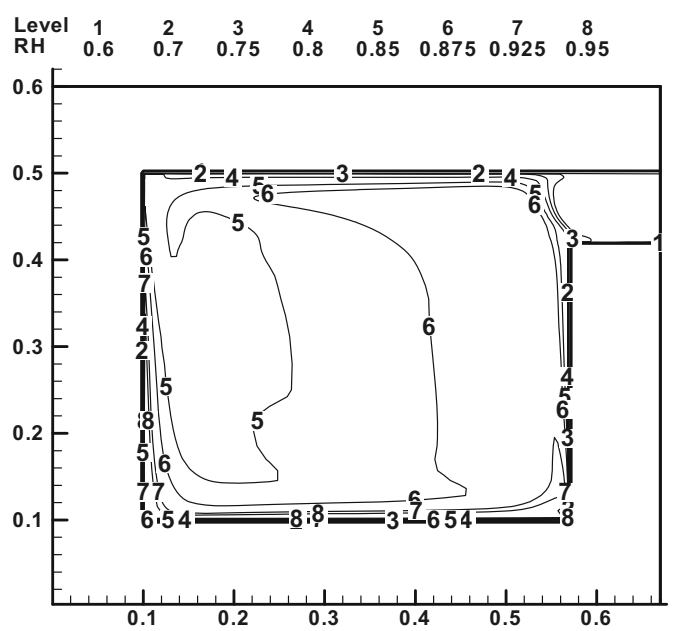

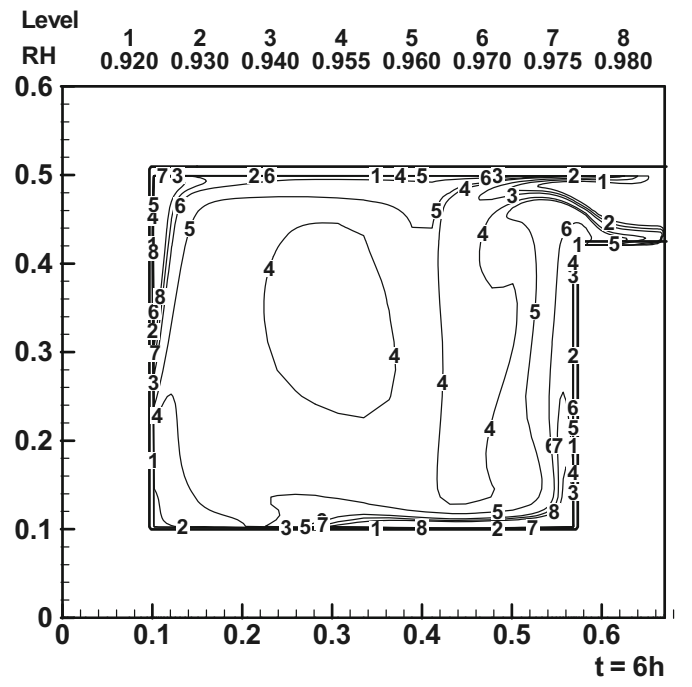

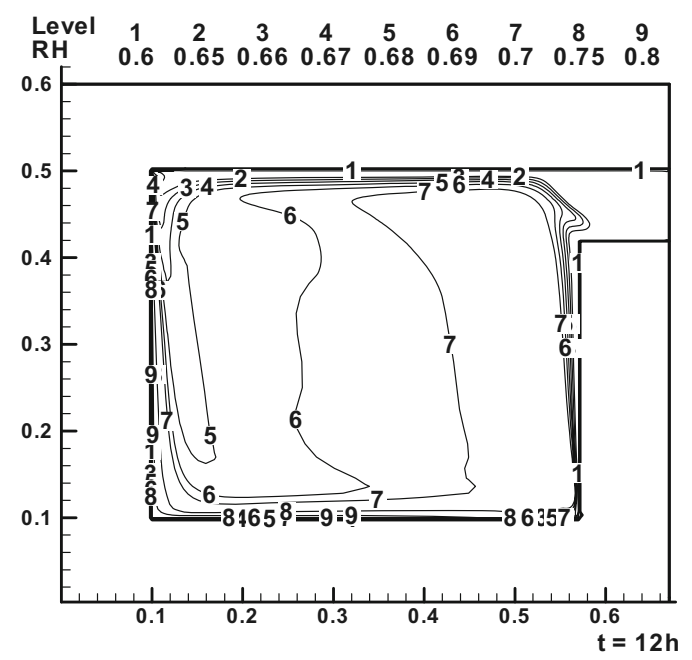

Fig. 4 a: $t=6 \mathrm{~h}(\mathrm{am}) ; \mathrm{Text}=15^{\circ} \mathrm{C} ; \mathrm{RHext}=90 \%$. b: $\mathrm{t}=12 \mathrm{~h}\left(\right.$ noon); $\mathrm{Text}=20^{\circ} \mathrm{C} ; \mathbf{R H}=60 \% . \mathrm{c}: \mathrm{t}=18 \mathrm{~h}(6 \mathrm{pm}) ; \mathrm{Text}=15{ }^{\circ} \mathrm{C} ; \mathrm{RH}=90 \% . \mathrm{d}: \mathrm{t}=\mathbf{0} \mathrm{h}$ (midnight); Text $=10^{\circ} \mathrm{C} ; \mathbf{R H}=90 \%$

As previously shown [1], a very similar mainly counter clockwise wise fluid circulation takes place inside the volume and all along the inner walls, in the two cases.

Figures 3c: at $t=18 \mathrm{~h}(6 \mathrm{pm})$, Text $=15^{\circ} \mathrm{C}$.

In the two cases the behaviour is very similar with a "buffer effect" (very small speeds of exchanges) at the structure entrance. This effect results from the continuous external temperature decreasing from $12 \mathrm{~h}$ (noon) up to $24 \mathrm{~h}(0 \mathrm{~h}$ or midnight) and the beginning of the temperature difference reversal between outside and inside. However, we can note a mainly counter clockwise wise all along the inner walls but slightly more important, to the inside, at $18 \mathrm{~h}(6 \mathrm{~h} \mathrm{pm})$ than at $0 \mathrm{~h}$ (midnight), to the outside, in the case of the wet bottom wall.

Figures $3 \mathrm{~d}$, at $t=0 \mathrm{~h}$ (midnight), Text $=10^{\circ} \mathrm{C}$.

In the two cases (inside wet or dry bottom wall) it appears that the temperature gradients inside the marble walls and inside the volume are not so different. There are little exchanges between inside and outside air ("buffer effect") and the isotherms distributions show a mainly clockwise circulation all along the inside walls in relation with the positive difference between the inside and outside temperature (see Figures 6a).

\subsubsection{Relative iso-humidity evolutions}

The following Figs. 4 represent the evolution of the isohumidity curves inside the volume and, as for the isothermal curves, they are also depending on the considered moment. The relative hygrometry variations scales (level RH /100\%) take a look of the hygrometrical behaviour at each moment in the two cases considered.

Figures 4: at $\mathbf{6 h}(\mathrm{am})$, there is a renewing of the air inside the volume through the orifice during the outside temperature increasing period since midnight $(0 \mathrm{~h})$ up to noon $(12 \mathrm{~h})$. The 
C

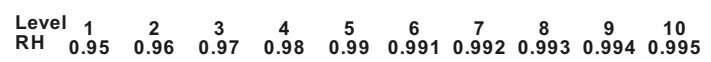

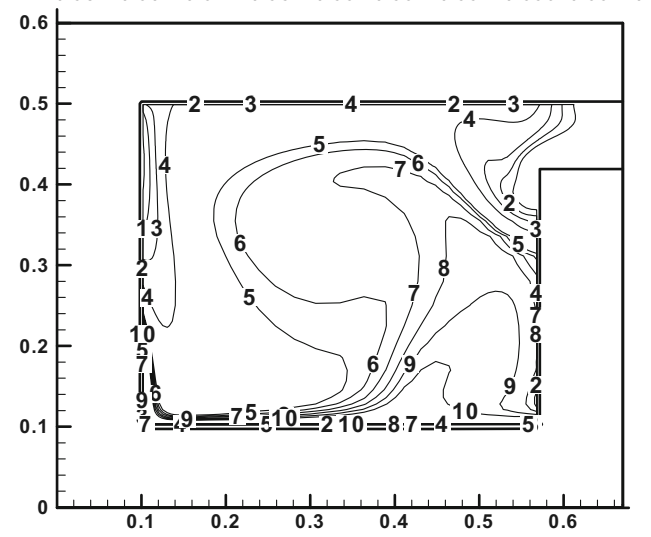

D

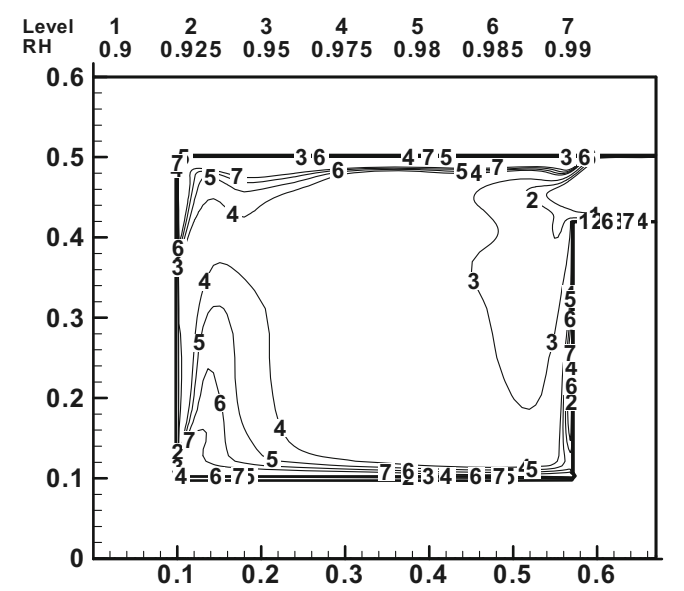

Fig. 4 (continued)

inner fluid circulation is modified for the wet bottom wall and is now mainly clockwise inside the volume as for the case of the dry one.

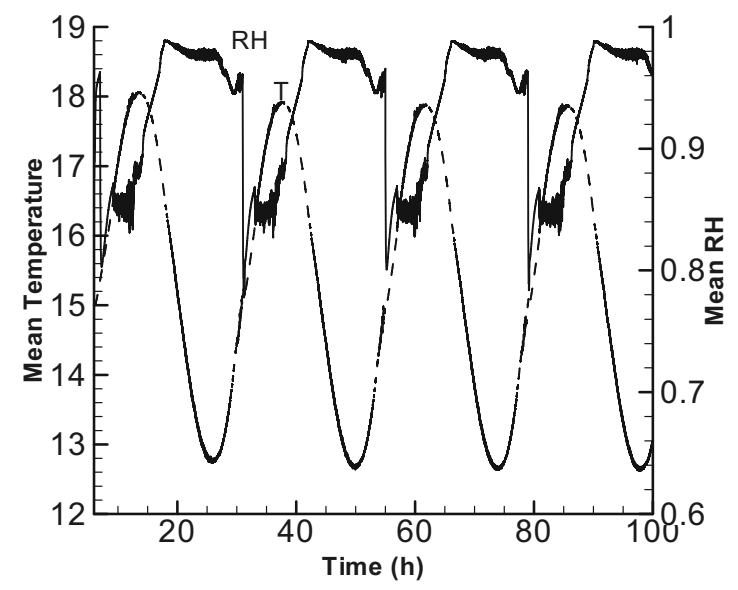

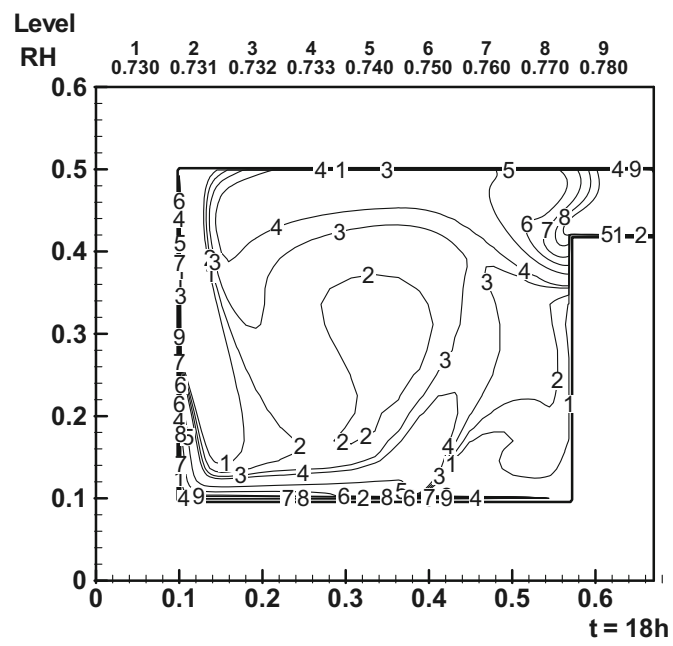

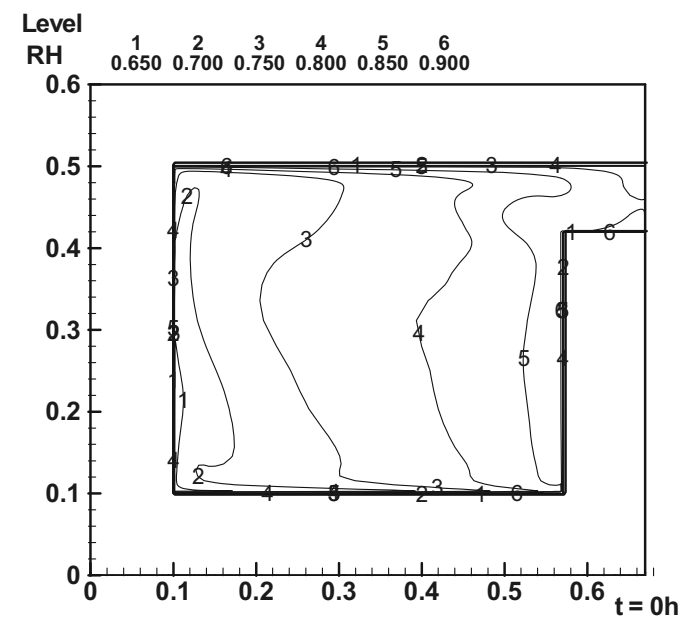

In the case of the wet bottom, possibilities of condensation are increased by a lower speed of the fluid circulation and are again higher all along the inner walls and in the volume $(\mathrm{RH}>96 \%)$.

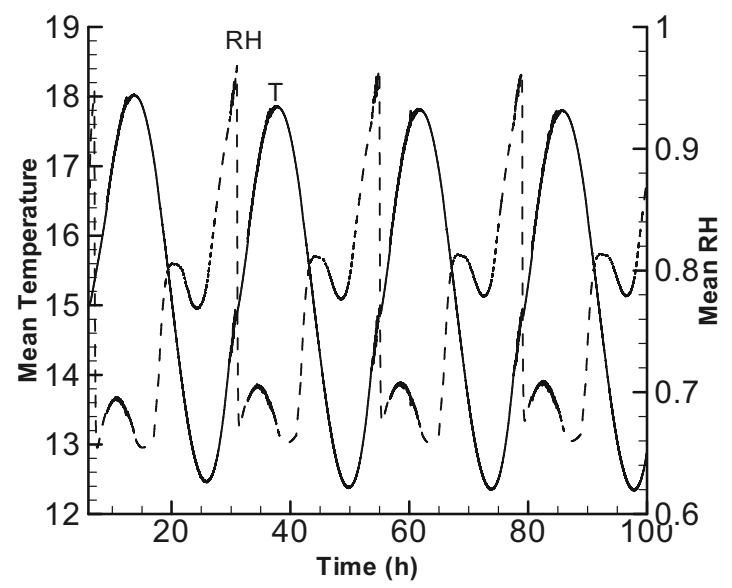

Fig. 5 Mean temperature and hygrometry evolutions of the air inside the volume 

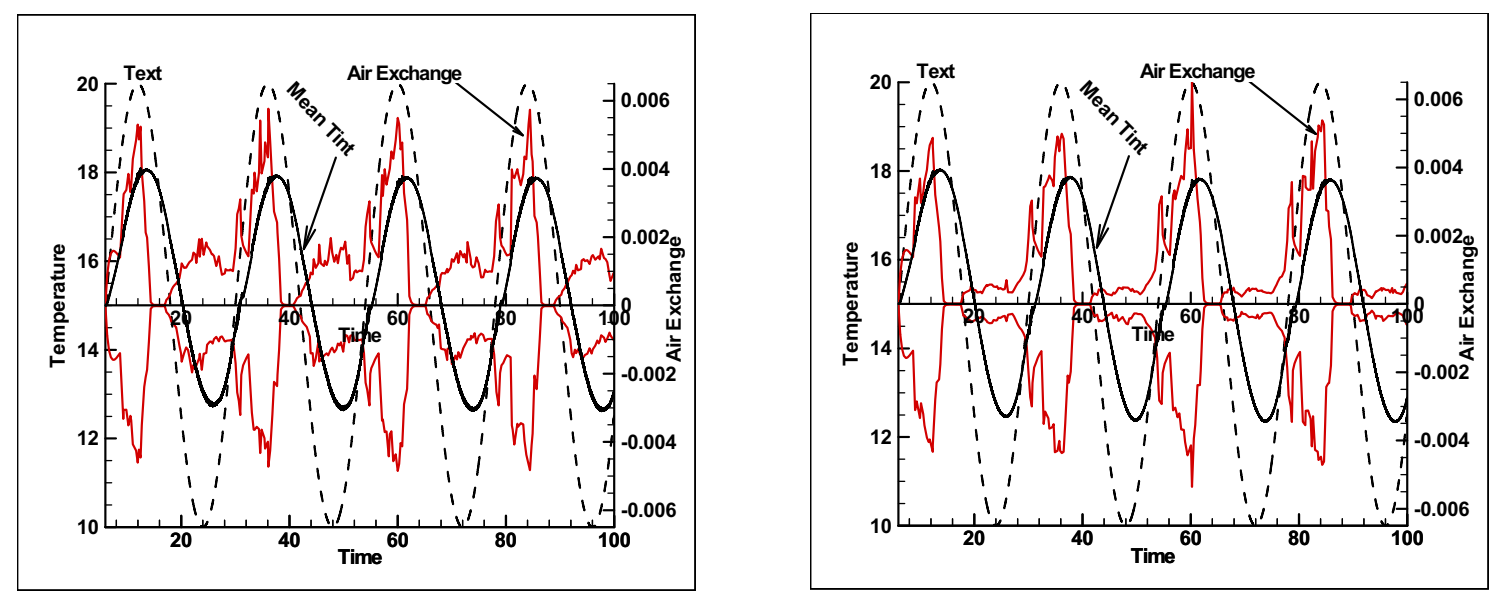

B
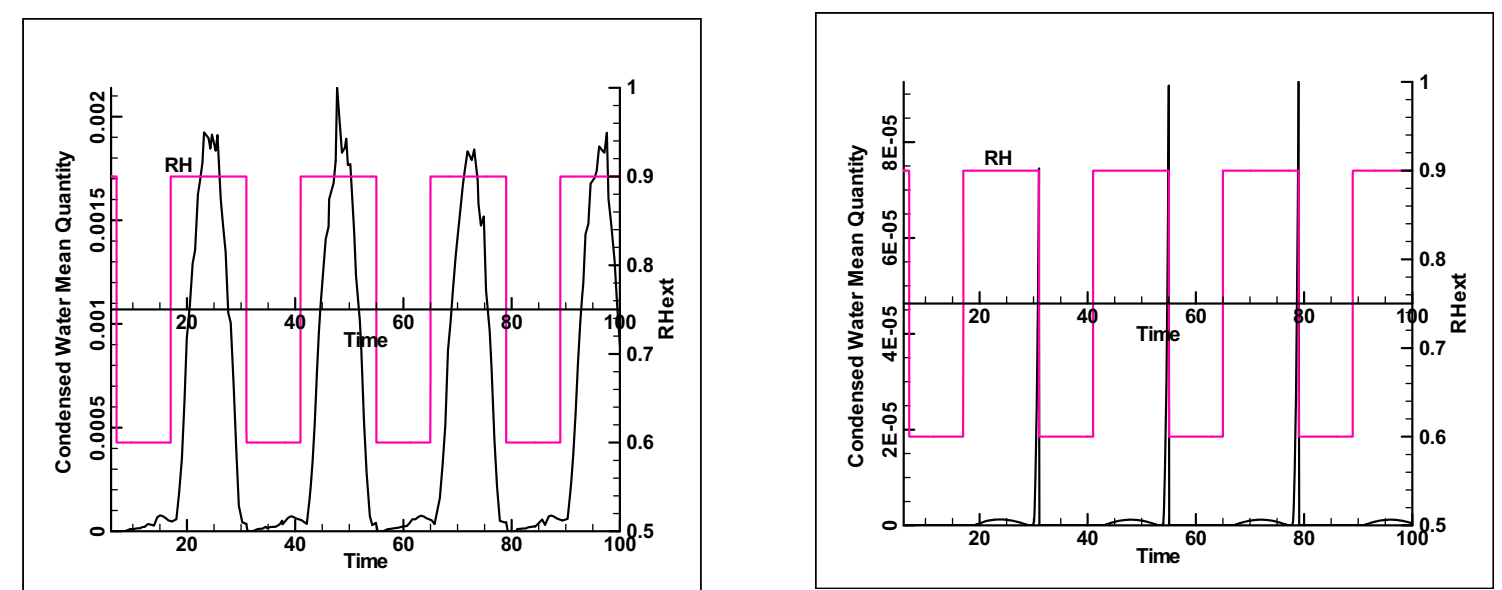

Fig. 6 a Air exchanges between outside and inside of the structure in relation with the temperature differences. b: Evolution of the mean quantity of condensed water vapour in relation with $\mathrm{RH}$

Figures $4 \mathrm{~b}$ : at $t=12 \mathrm{~h}$ (noon), for the same external constraints $\left(T=20^{\circ} \mathrm{C} ; \mathrm{RH}=60 \%\right)$, the circulation inside the volume is mainly counter clockwise wise in the two cases, but the iso-humidity distribution reaches higher values in the case of the wet bottom: higher than $85 \%$ and up to $90 \%$ in the main part of the volume when, for the dry bottom wall, RH maximal value is in a $\sim 70-75 \%$ range, the highest $\mathrm{RH}$ values taking place all along the walls.

In the two cases the highest RH values are obtained on the farthest parts of the adiabatic walls facing the orifice.

Figures 4c: at $\boldsymbol{t}=\mathbf{1 8} \mathbf{h}(6 \mathrm{~h} \mathrm{pm})$, for the same external constraints $\left(T=15{ }^{\circ} \mathrm{C} ; \mathrm{RH}=90 \%\right)$, the circulation inside the
Fig. 7 Phase $\varphi=0$; Day after day evolution of the yield of water vapour condensation $(\eta)$
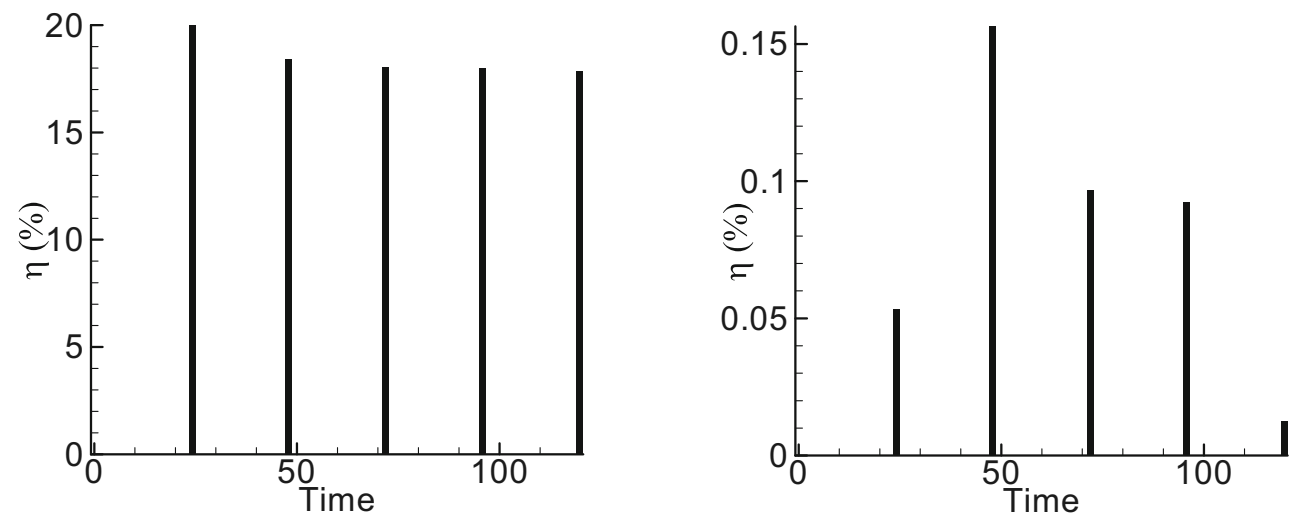
volume, acting on the iso-humidity distribution, happens as counter clockwise wise (from outside to inside) for the wet bottom as for the dry bottom. In these conditions it appears clearly that the relative humidity inside the volume is relatively homogeneous, but it is always higher in the case of the wet bottom than for the dry one.

With a wet bottom there are very high condensation possibilities ( $\mathrm{RH}>97 \%$ ), enhanced essentially all along the adiabatic walls, and in the main part of the volume. On the contrary, at the same time, for the dry bottom wall, a "drying" effect takes place downing RH about $75 \%$ when the external RH imposed $=90 \%$.

Figures $4 \mathbf{d}$, at $\boldsymbol{t}=\mathbf{0} \mathbf{h}$ (midnight), for the same external constraints conditions ( $\mathrm{T}$ and $\mathrm{RH}$ ), circulation inside the volume, acting on the iso-humidity distribution, is in an opposite direction for the two cases: anti-clock wise for the wet bottom, clockwise for the dry one.

In the case of the wet bottom, we point out a condensation possibility relatively high $(\mathrm{RH}>95 \%)$ in the vicinity of the walls under constraints and in the volume when, in the case of the dry bottom, for the same external $\mathrm{RH}=90 \%$, a "drying" effect takes place in the volume, reducing RH down to $\sim 65$ $70 \%$, as for the one observed for the results obtained at $18 \mathrm{~h}$ (6 pm).

\subsubsection{Resulting condensation effects}

Nevertheless, a global view of this behaviour (by numerical integration of the variables in space) is better illustrated by the evaporation / condensation phenomena taking place inside the structure.

In the conditions defined as $\varphi=0 \mathrm{~h}$ (Fig. 2), we can see in figs. 5 that mean temperature and hygrometry values, inside the structure, have an evolution in direct relation with these external and synchronous conditions.

It appears clearly that the RH increasing inside the volume starts in the same way at the same time in the two cases.

The maxima ( $\mathrm{RH}>70 \%)$ take place with the same $24 \mathrm{~h}$ period in the two cases but starting at $7 \mathrm{~h}(\mathrm{am})$ for the wet bottom when it is at only $13 \mathrm{~h}(1 \mathrm{pm})$ for the dry one.

In the wet bottom case this increase starting at $7 \mathrm{~h} \mathrm{(am)}$ from $\sim 76 \% \mathrm{RH}$, after a first step at $\sim 84 \%$, is rising up and can reach more than $98 \%$ during about $8 \mathrm{~h}$, to fall drastically to the initial internal value $(\sim 74 \%)$ at $\sim 6-7 \mathrm{~h}$ am.

With the dry bottom wall, as previously presented [1], the condensation phenomenon, even if it is low, is however not negligible. Its condensing temporal variation starts at about 7 am, with a first top around $70 \% \mathrm{RH}$, followed by a second one $(\sim 80 \%)$, starting at only $13 \mathrm{~h}(1 \mathrm{pm})$, and, immediately after, at around midnight (24 h), a third increase rising up to 95\% RH. Then a drastic RH falling (transition from condensation to evaporation) takes place and ends at 7 am the next day.
Presence of a thin layer of water vapour induces a shorter dephasing of around $6 \mathrm{~h}$ and a more important duration period for the highest RH inside the structure in the considered phase $\varphi$ conditions $(\mathrm{T} / \mathrm{RH}=0 \mathrm{~h})$.

In the two cases however, internal RH is always higher than the external lower value imposed (60\%).

Figures 6 show the evolution of the air exchanges between outside and inside of the structure in relation with the external temperature and $\mathrm{RH}$ variations and the resulting mean quantity of condensed water vapour.

Figures 6a Thermal inertia of the constrained marble walls induces the late of about $2 \mathrm{~h}$ between the external temperature evolution (dashed line) and the resulting internal one (continuous line). That leads to reduce the inner temperature variations inside the volume. In the two considered cases these variations are around $15,4 \pm 2,6{ }^{\circ} \mathrm{C}$ for the wet bottom and $15,3 \pm 2,7^{\circ} \mathrm{C}$ for the dry one which can be compared with the external $15 \pm 5^{\circ} \mathrm{C}$ (see also Figs. 5)

The temperature difference between outside and inside air, at the same time, explain the dynamics of the air exchanges and how the external increasing temperature period is acting as a "thermal driving force" from 6 am to $12 \mathrm{~h}$ (noon) leading to the renewing of the relative humidity inside the volume.

However, if the main exchanges occur principally between $6 \mathrm{~h}(\mathrm{am})$ and $13 \mathrm{~h}(1 \mathrm{pm})$, it appears that lower exchanges, increased in the wet bottom case, can also take place during the period when the mean internal temperature is higher than the external one.

Consequently, as it can be seen in the figs. 5, internal RH was modified by this air renewing in relation with the external RH imposed. This induces modifications of the in-time cumulated water quantities (ratio between the condensed water and the water vapour quantity contained in the volume at the initial moment).

Figures $6 \mathrm{~b}$ show the relation between $\mathrm{RH}$ variation and evolution of the mean quantity of condensed water vapour inside the volume.

For the wet bottom case it can be seen, by comparing the Figs. $6 \mathrm{a}$ et $6 \mathrm{~b}$, that, for the external conditions imposed $(\varphi=$ 0 ), the main condensation process takes place during the time when there is a maximal negative temperature difference between Text and Tint and when the introduced external RH is at its maximal value.

For the dry bottom, the feeble condensation effect takes place during the periods when the air exchanges are low or during a very short time limited, in the two cases, by the drastic external RH decrease from $90 \%$ to $60 \%$ at $7 \mathrm{~h}$ am.

The relation with the drastic RH decrease and the reversal of this temperature difference between outside and inside air, due to an about $2 \mathrm{~h}$ delay (influence of the marble walls) induces the evolution of the mean quantity of condensed water vapour. These mean condensed water quantities can be about 25 times higher in the case of the 


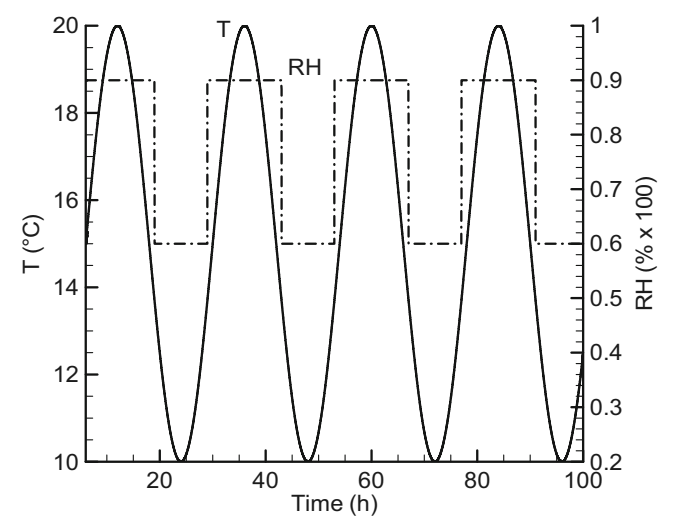

Fig. 8 Phase $\varphi=12$ h.: Temperature (T) and relative humidity (RH) temporal evolutions of the external air (boundary conditions on the constrained walls $): \mathrm{T}\left({ }^{\circ} \mathrm{C}\right)=\mathrm{Text}=$ external temperature

wet bottom wall than for the dry one, with a mean duration of the water production (area of the piks) of the order of $10 \mathrm{~h}$ for the wet bottom instead of $1 \mathrm{~h}$ for the dry one.
These Figs. 6, over 4 days, indicate also that, in these imposed external conditions, a steady-state effect is always obtained in 3 days but more rapidly in the case of the wet bottom wall (from the first day).

To better quantify the daily hydrometric exchanges between the outside and inside of the volume, the temporal study domain is subdivided in $24 \mathrm{~h}$ length intervals of the type [ $t_{0}-$ $24, t_{0}\left[\right.$ with $t_{0}=24,48,72, \ldots$, etc. Then we have defined the percentage of daily condensed water vapour by the following equation as a function of phase, whatever the hygrometric state of the bottom wall is:

$\eta\left(t_{0}\right)=\frac{\int_{t_{0}-24}^{t_{0}}\left|q_{e}(t)-q_{o}(t)\right| d t}{\int_{t_{0}-24}^{t_{0}}\left|q_{e}(t)\right| d t} \times 100 \%$

Figures 7 shows the day after day evolution over 5 days of the mean condensed water vapour ratio. The maximum is reached and stabilized in $\sim 3$ days for the two types of bottom wall studied.

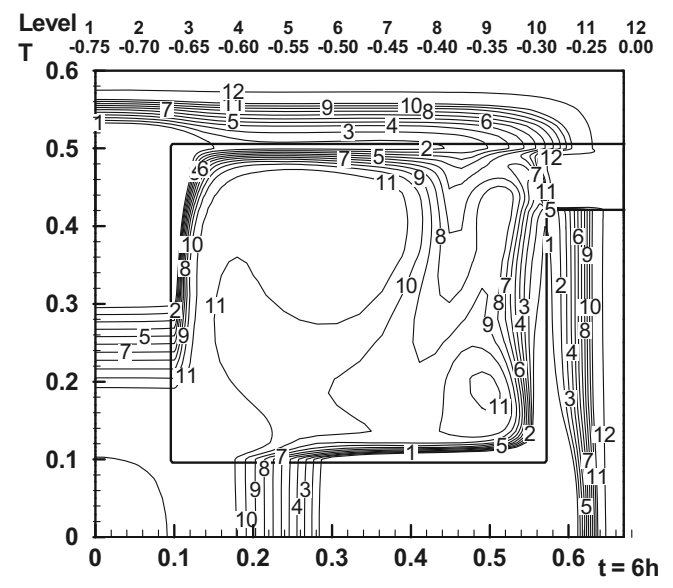

B

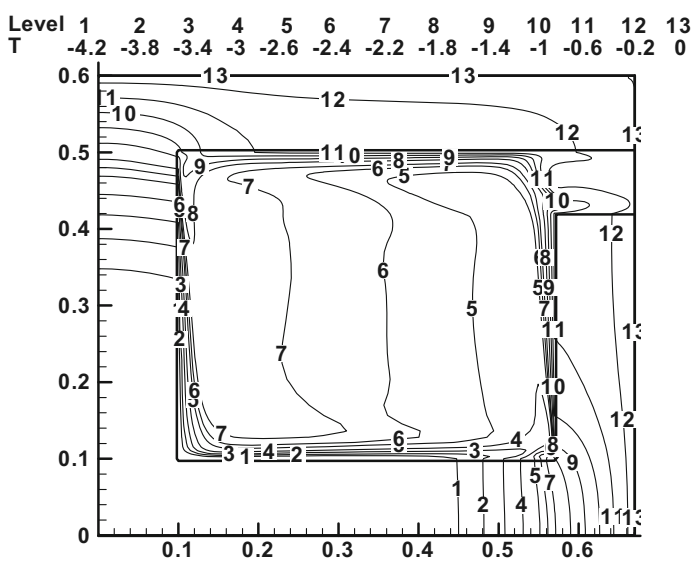

A

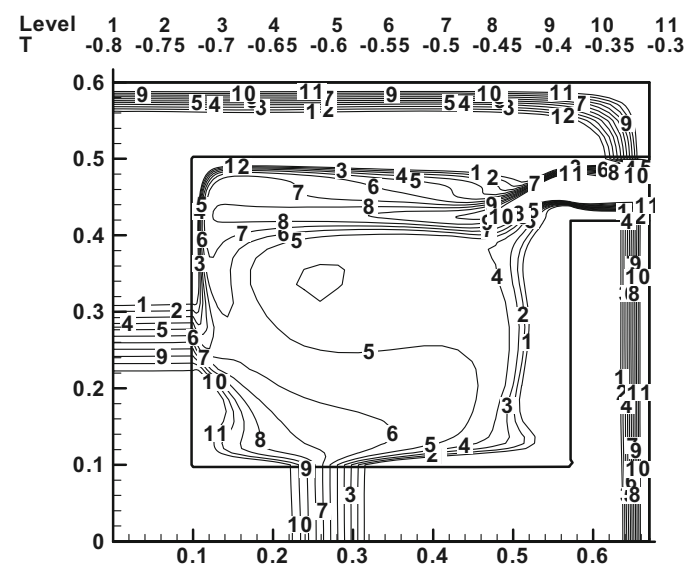

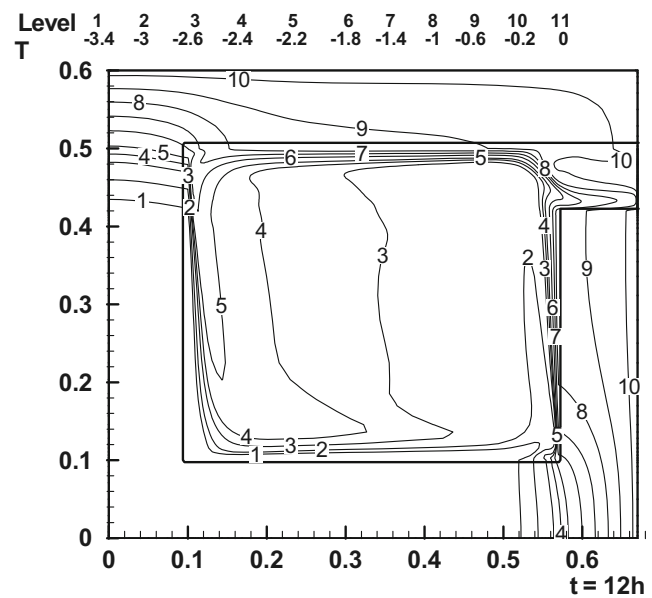

Figs. 9 a: $\mathbf{t}=\mathbf{6} \mathbf{~ h}(\mathbf{a m}) ; \mathbf{T e x t}=\mathbf{1 5}{ }^{\circ} \mathbf{C} ; \mathrm{RH}=90 \% ; \mathrm{b}: \mathbf{t}=\mathbf{1 2} \mathbf{~ h}(\mathbf{n o o n}) ; \mathbf{T e x t}=\mathbf{2 0}{ }^{\circ} \mathbf{C} ; \mathrm{RH}=90 \%$. c: $\mathbf{t}=\mathbf{1 8} \mathbf{~ h}(\mathbf{6} \mathbf{~ p m}) ; \mathbf{T e x t}=\mathbf{1 5}{ }^{\circ} \mathbf{C} ; \mathrm{RH}=90 \%$. d: $\mathbf{t}=\mathbf{0} \mathbf{h}$ (midnight); $\mathbf{T e x t}=\mathbf{1 0}^{\circ} \mathrm{C} ; \mathrm{RH}=60 \%$ 


\section{C}

$\begin{array}{lllllllcccc}\text { Level 1 } & 2 & 3 & 4 & 5 & 6 & 7 & 8 & 9 & 10 \\ \text { T } & 0.5 & 0.6 & 0.7 & 0.8 & 0.9 & 1 & 1.1 & 1.2 & 1.3 & 1.4\end{array}$

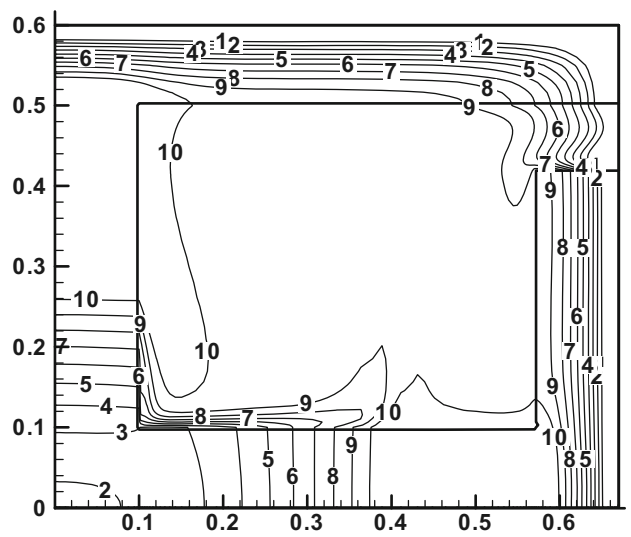

D

$\begin{array}{llllllllllll}\text { Level } & 1 & 2 & 3 & 4 & 5 & 6 & 7 & 8 & 9 & 10 & 11 \\ \mathrm{~T} & 0.1 & 0.5 & 1 & 1.5 & 2 & 2.5 & 3 & 3.5 & 4 & 4.5 & 5\end{array}$

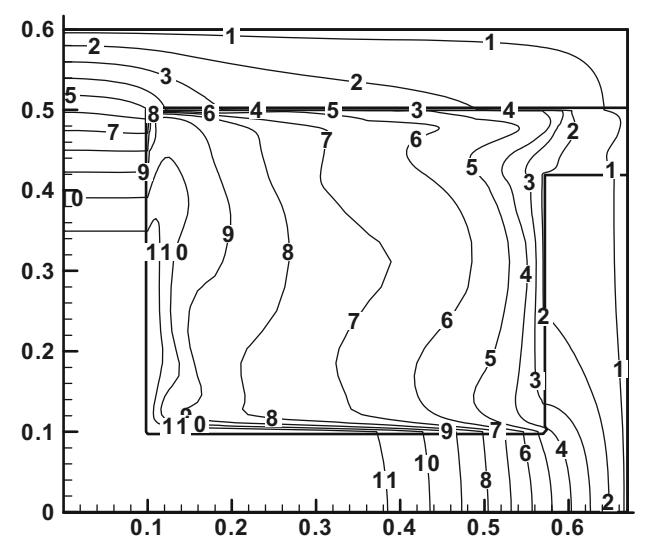

Fig. 9 (continued)

For the wet bottom case, this maximum is reached about $1 \mathrm{~h}$ early than the dry bottom one, and more rapidly, from the first day before to be quasi stabilized in a $17-18 \%$ range in the following days.

For the dry bottom, the maximal yield is only reached at the end of the second day but is not stabilized and appears limited to a very low value.

In the imposed conditions studied and from the results obtained $(\varphi=0 \mathrm{~h})$ it appears that this thin layer of wet air $(3 \mathrm{~mm}$; $90 \% \mathrm{RH}$ ) leads to a more efficient condensation process and acts as a starter and a feed-back for the condensation inside the volume.

To determine more precisely the role of the phase $\varphi=\mathrm{T} /$ $\mathrm{RH}$ on the possibilities of condensation of the water contained in air, we have modified the position in time of the maximal relative humidity in relation with temperature. In these new conditions the highest RH (90\%) period is now centred at $12 \mathrm{~h}$ (noon) when previously it was centred at midnight $(0 \mathrm{~h})$. The
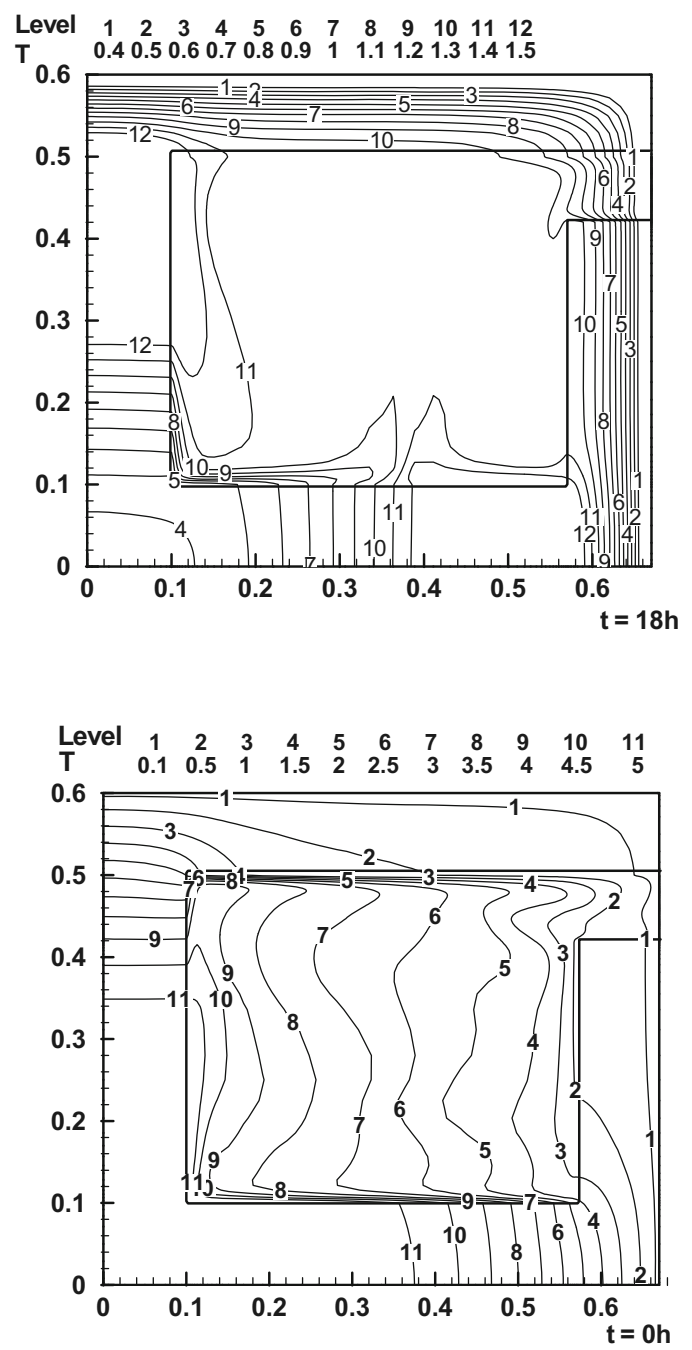

new $\mathrm{RH}$ crenelled variation being $12 \mathrm{~h}$ shifted regarding the applied sinusoidal external temperature. Consequently, the so modified relation between T and RH is named phase $\varphi=12 \mathrm{~h}$.

\subsection{Phase $\varphi=12 \mathrm{~h}$}

Figure 8 represents the new external conditions imposed to the structure: temperature $(\mathrm{T})$ and relative humidity $(\mathrm{RH})$ evolutions of the external air applied to the constrained walls (boundary conditions of the model).

Coincidences between maxima and minima of temperature (T) and relative hygrometry (RH) are in an opposite way with the phase $\varphi=0 \mathrm{~h}$. The highest RH (90\%) is now centred at $12 \mathrm{~h}$ (noon), starting from $5 \mathrm{~h}$ (am) up to $19 \mathrm{~h}(7 \mathrm{~h} \mathrm{pm})$, and the lowest RH $(60 \%)$ is centred at $0 \mathrm{~h}$ (midnight), from $19 \mathrm{~h}$ ( $7 \mathrm{~h} \mathrm{pm}$.) up to $5 \mathrm{~h}(\mathrm{am})$ the next morning.

Now we present the more significant results obtained in a same manner as for $\varphi=0 \mathrm{~h}$, by beginning from the 
synchronized boundary conditions at $t=6 \mathrm{~h}(\mathrm{am})$. We will use the same presentation as for $\varphi=0 \mathrm{~h}$ : at left the inside wet bottom wall and at right the inside dry bottom wall.

The following Figs. 9 and 10 represent the local temperature and relative hygrometry distribution in the width section.

\subsubsection{Isotherms}

Figures 9 represent the isotherms evolution inside the structure at various moments.

By comparing figs. 3 and figs. 9, at the same times, thermal distribution inside the walls and the volume are the same as for $\varphi=0 \mathrm{~h}$ at about some details. In the structure volume this thermal distribution induces a main clock-wise circulation.

In these new imposed conditions named phase $\varphi=12 \mathrm{~h}$, the isotherms show convective movements (figs. 9), due to temperature steps relatively important in some cases. In the

A

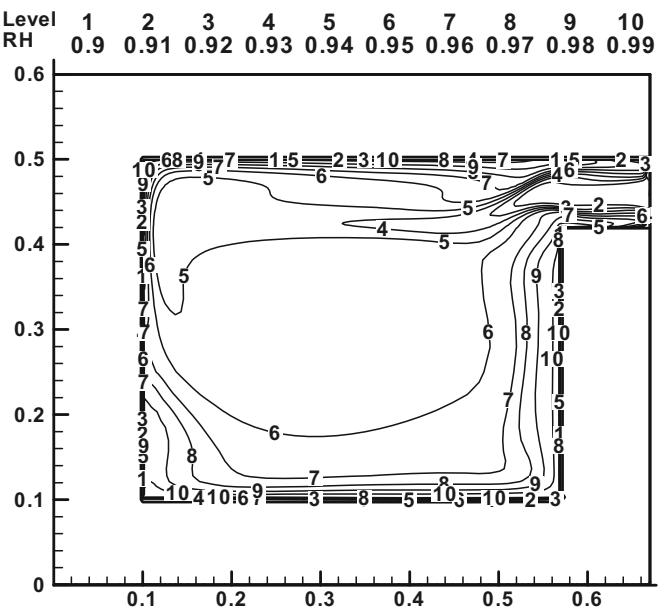

B

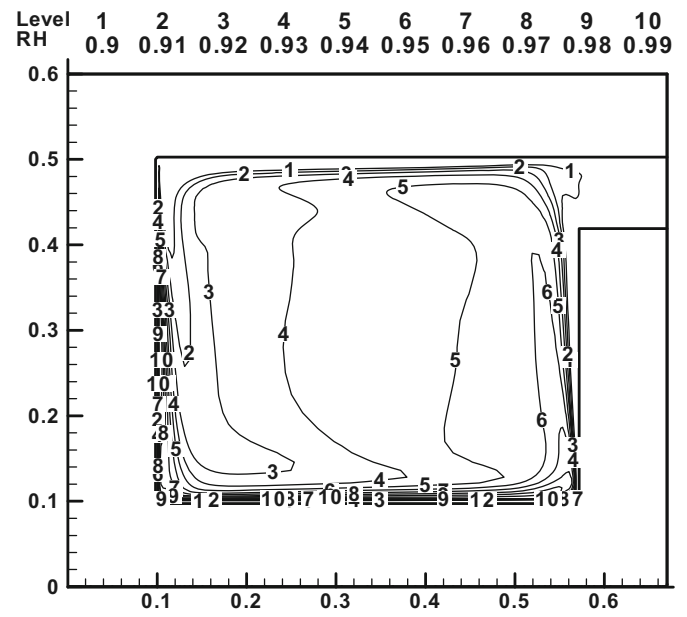

dry bottom wall case, with regard to the external temperature (Text), gap values can reach $\sim 5^{\circ} \mathrm{C}$ near the adiabatic walls at $0 \mathrm{~h}$ (midnight) and can be lower than $-2,5^{\circ} \mathrm{C}$ on the same walls at $12 \mathrm{~h}$ (noon).

This demonstrates the main role of the thermal inertia of the walls and of the "thermal driving force" acting on the internal circulation.

\subsubsection{Iso-humidity}

Figures 10: deal with the relative humidity evolutions inside the structure at various moments.

A humidity concentration relatively high in the vicinity of the orifice and on the walls submitted to the constraints at $6 \mathrm{~h}$ (am) (fig. 10), $12 \mathrm{~h}$ (noon) (Fig. 10b) and $18 \mathrm{~h}(6 \mathrm{pm}$ ) (Fig. 10c), when the external relative hygrometry is the highest (90\%). That causes an internal condensation all along
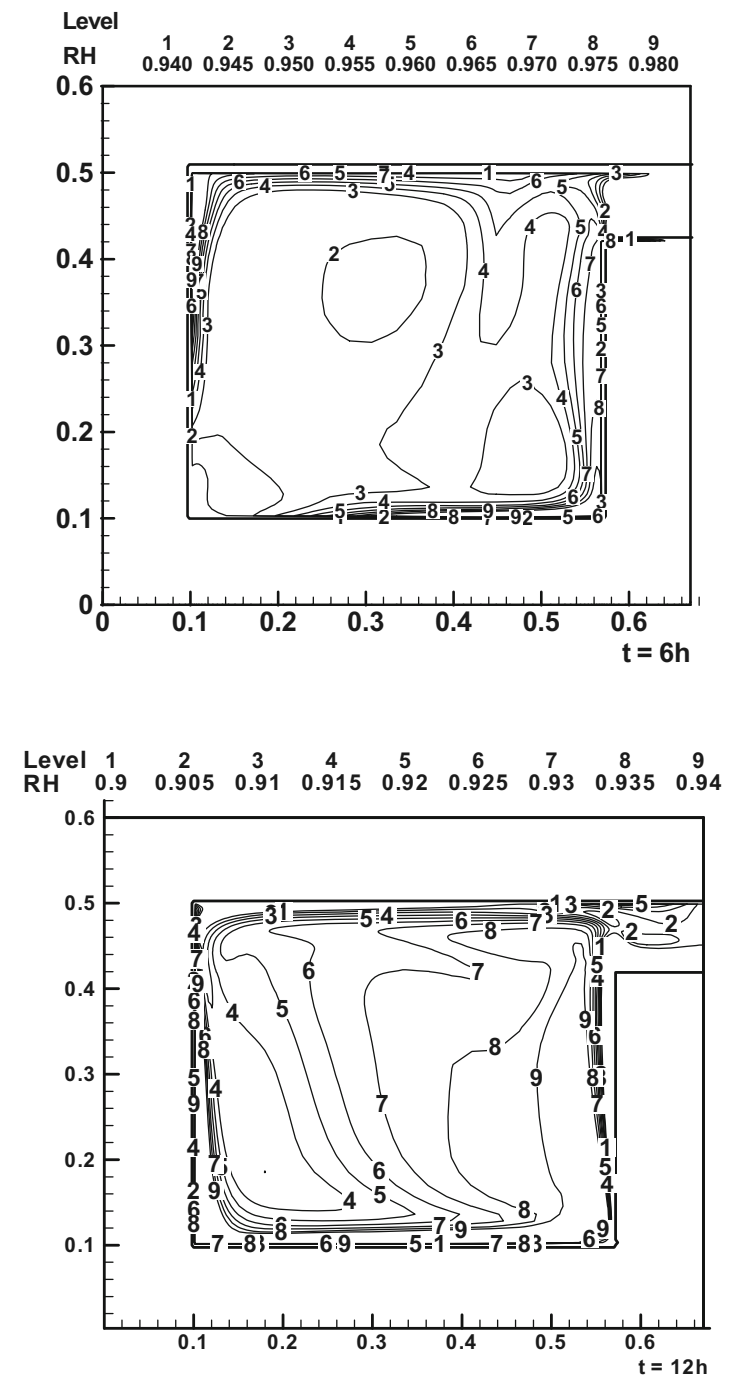

Fig. 10 a: $t=6 \mathrm{~h}(\mathrm{am}) ; \mathrm{Text}=15^{\circ} \mathrm{C} ; \mathbf{R H}=90 \% . \mathrm{b}: \mathrm{t}=12 \mathrm{~h}\left(\right.$ noon); $\mathbf{T e x t}=20^{\circ} \mathrm{C} ; \mathbf{R H}=90 \% . \mathrm{c}: \mathrm{t}=18 \mathrm{~h}(6 \mathrm{pm}) ; \mathrm{Text}=15^{\circ} \mathrm{C} ; \mathbf{R H}=90 \% . \mathrm{d}: \mathrm{t}=\mathbf{0} \mathrm{h}$ (midnight); Text $=10^{\circ} \mathrm{C} ; \mathrm{RH}=60 \%$ 


\section{C}

\begin{tabular}{ll|cccccccccc} 
Level & 1 & 2 & 3 & 4 & 5 & 6 & 7 & 8 & 9 & 10 & 11 \\
$\mathrm{RH}^{2}$ & 0.9 & 0.91 & 0.92 & 0.93 & 0.94 & 0.95 & 0.96 & 0.97 & 0.98 & 0.99 & 0.992
\end{tabular}

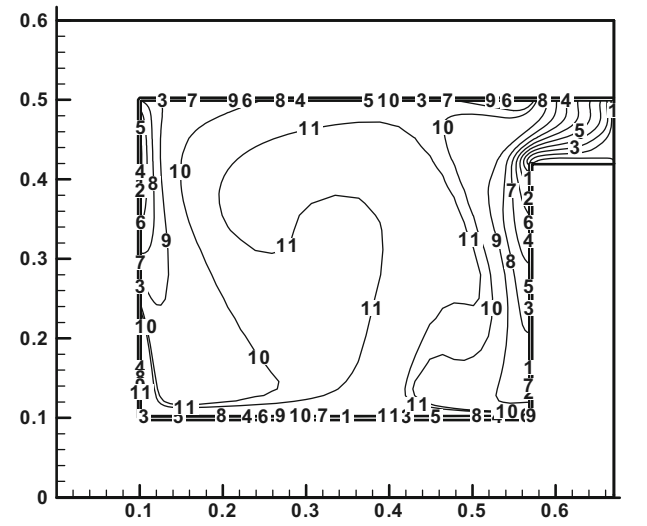

D

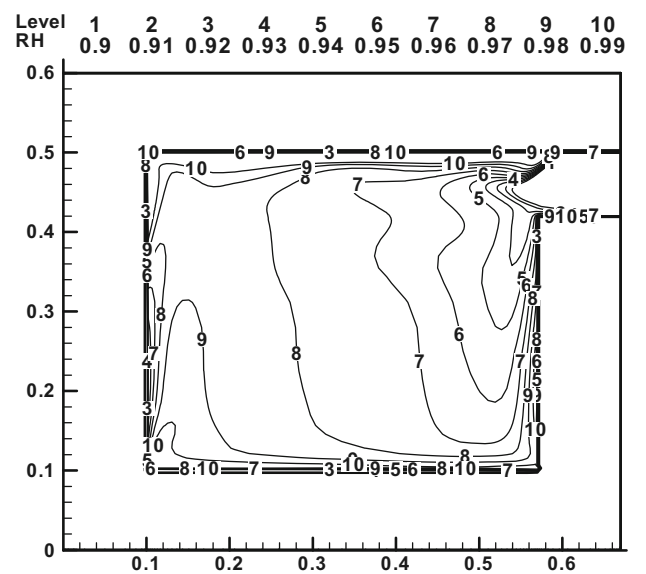

Fig. 10 continued.

the walls, essentially at $6 \mathrm{~h}$ (am) (fig. 10) in the dry bottom wall case.

The hygrometry dispatch remains relatively homogeneous out of these zones in the dry bottom wall case essentially at $0 \mathrm{~h}$
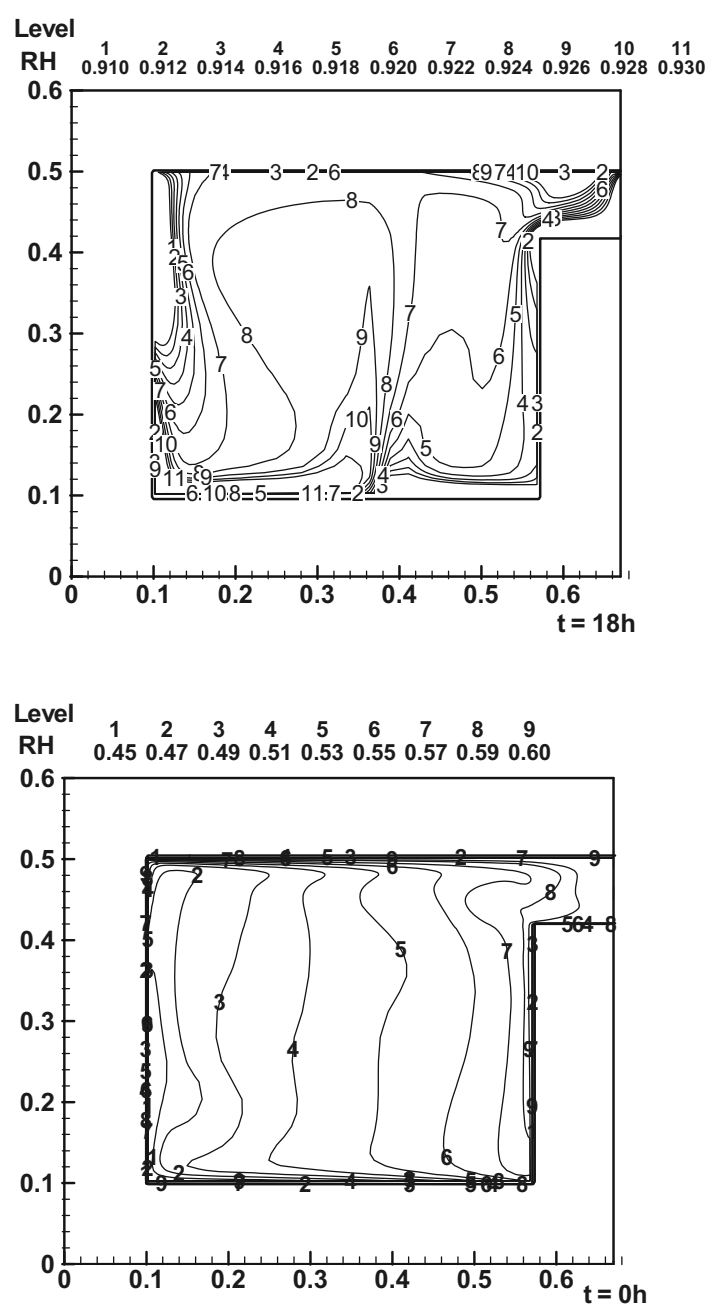

and $12 \mathrm{~h}$ (noon) but only at $12 \mathrm{~h}$ (noon) for the wet bottom case.

At $t=12 \mathrm{~h}$ (noon) (Fig. 10b) the relative hygrometry distribution inside the volume is very similar in the $92-95 \%$

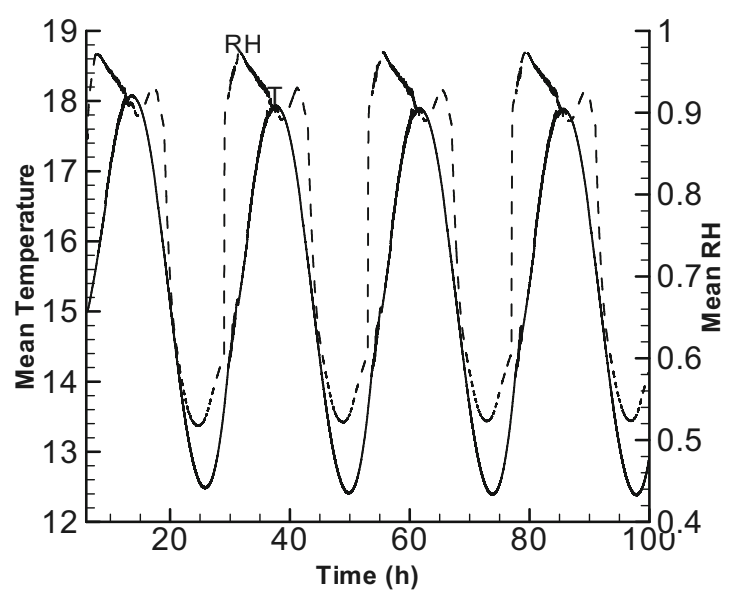

Fig. 11 Evolution of the inner temperature and RH inside the width section 
range but can reach saturation on the adiabatic walls for the wet bottom when it cannot trespass $95 \%$ for the dry one. Generally speaking humidity repartition inside the volume, which is submitted to driving rotating forces, is usually higher in the wet bottom case than in the dry one and saturation essentially takes place on the adiabatic walls.

In the Fig. 10d it appears that at $t=0 \mathrm{~h}$ (midnight), when external $\mathrm{RH}=60 \%$, the inner humidity is higher than $95 \%$ in the totality of the volume for the wet bottom case when for the dry bottom one we can observe a "drying" effect downing RH to $46 \%$ near the adiabatic walls in the opposite part of the orifice.

In the two cases, a driving clockwise circulation inside the volume is apparent in contrast with the counter clockwise wise circulation (from outside to inside) which is acting at $6 \mathrm{~h}$ (am), $12 \mathrm{~h}$ (noon) and $18 \mathrm{~h}(6 \mathrm{pm})$.

As we have shown in our previous paper (Batina and Peyrous [1]) dealing only with the dry bottom wall case, we can do some primary observations:

A

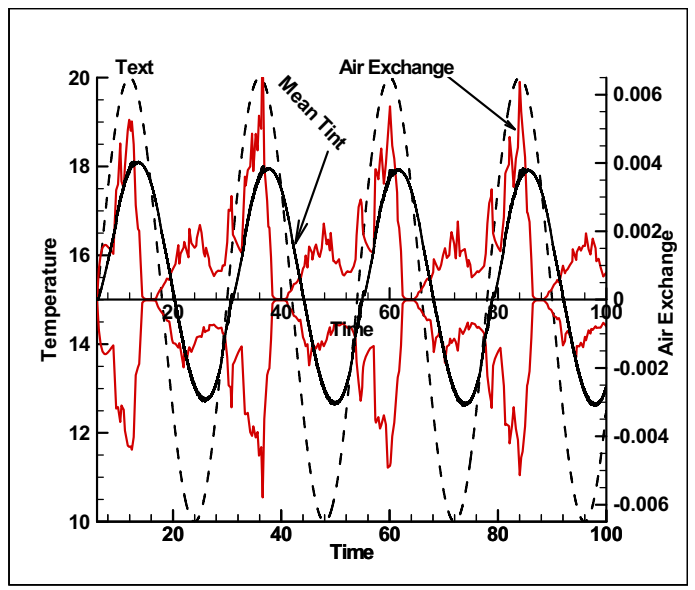

B

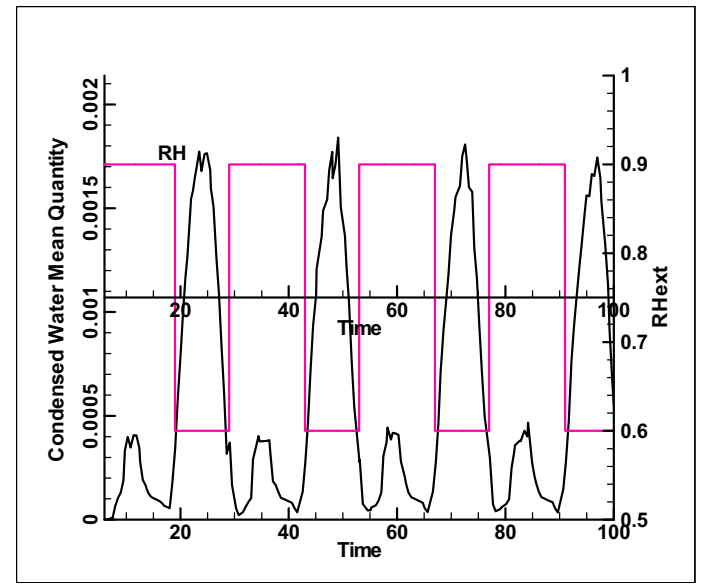

- with the phase $\varphi=0 \mathrm{~h}$, in the case of the inside dry bottom wall, an air "drying effect" can be seen at $t=18 \mathrm{~h}$ $(6 \mathrm{pm})$ and at midnight $(0 \mathrm{~h})$, falling RH away $~ 70 \%$ when the imposed $\mathrm{RH}=90 \%$.

- with the phase $\varphi=12 \mathrm{~h}$ this "drying effect" is only occurring at midnight $(0 \mathrm{~h})$ reducing $\mathrm{RH}$ to $\sim 45 \%$ when the imposed $\mathrm{RH}=60 \%$.

\subsubsection{Resulting condensation effects}

Figures 11 show the mean temperature and relative hygrometry of the air inside the volume for the two cases.

By comparing with the results obtained with $\varphi=0 \mathrm{~h}$ we can notice that, for this phase $\varphi=12 \mathrm{~h}$, in the case of the wet bottom the inner air temperature $\mathrm{T}$ is varying around 15,2 \pm $2,8^{\circ} \mathrm{C}$ and $\mathrm{RH}$ is always higher than $\sim 78 \%$ all along the time, in a $92-99 \%$ range during around $22 \mathrm{~h}$. The maximal value is reached at about $15 \mathrm{~h}(3 \mathrm{pm})$.
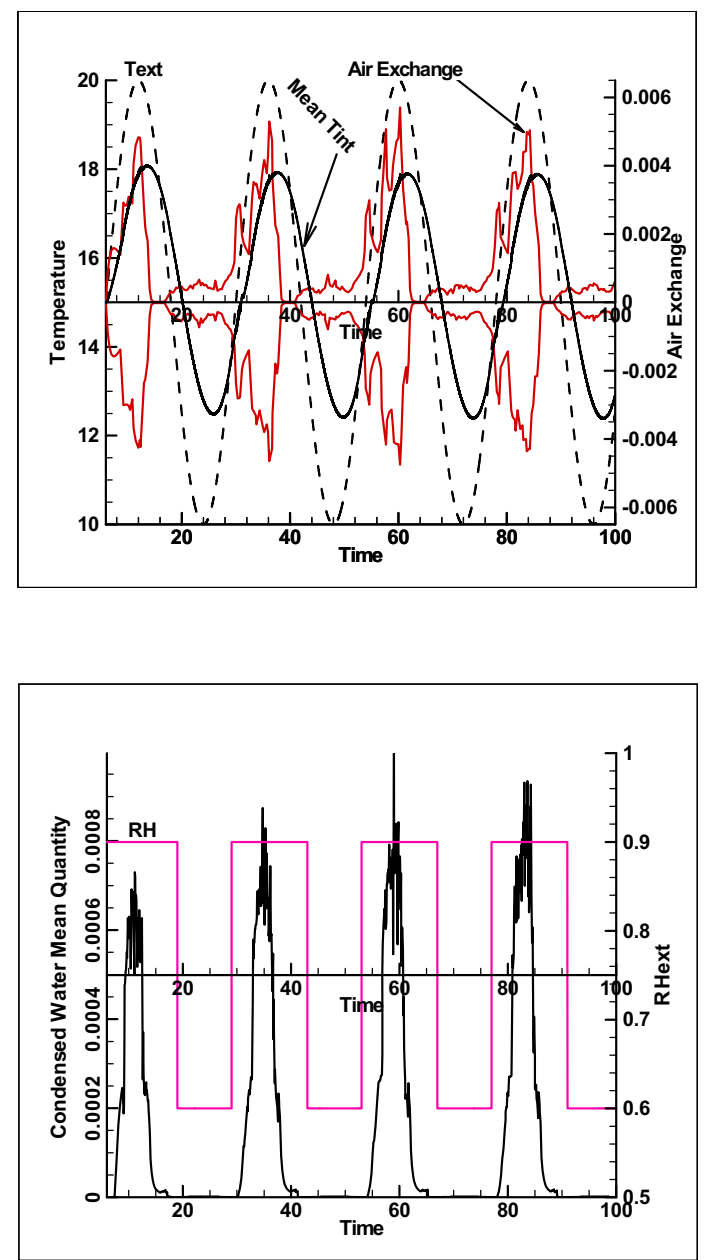

Fig. 12 a Air exchanges between outside and inside of the structure in relation with the temperature differences. b: Evolution of the mean quantity of condensed water vapour in relation with $\mathrm{RH}$ 
Fig. 13 Phase $\varphi=12$; day after day evolution of the yield of water vapour condensation $(\eta)$
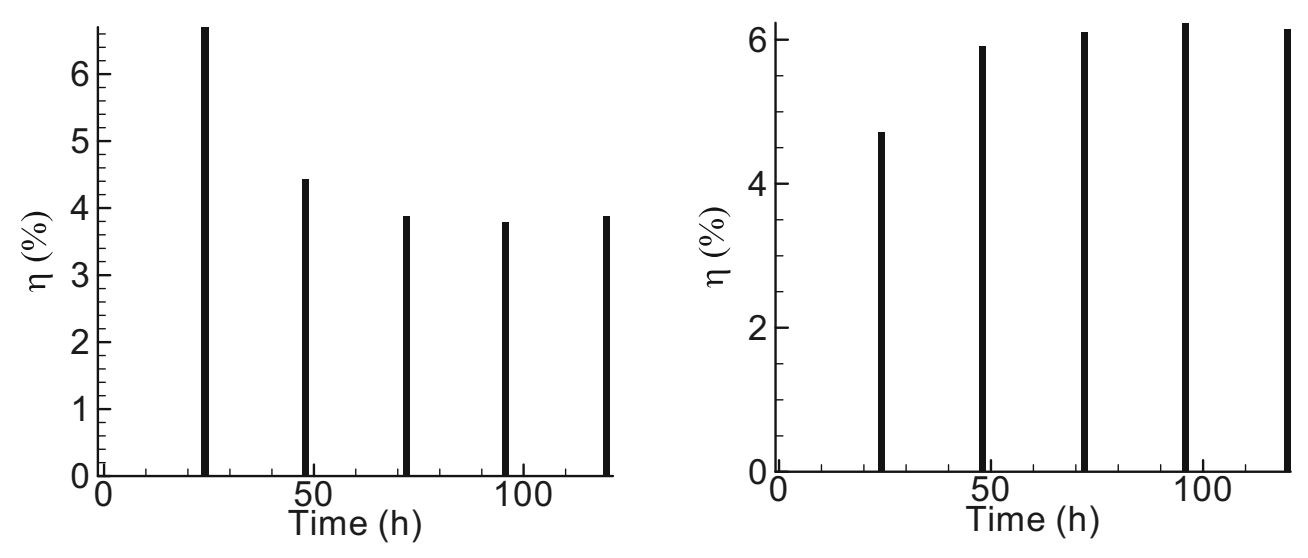

In the case of the dry bottom the maximal $\mathrm{RH}$ values, in a 90-96\% range, take place only from $5 \mathrm{~h}$ up to $19 \mathrm{~h}(7 \mathrm{pm})$ in accordance with the maximal external RH imposed.

The "drying effect", occurring around midnight $(0 \mathrm{~h})$, reducing to $\sim 45 \%$ the external imposed $60 \% \mathrm{RH}$, is confirmed.

In these new conditions, we can see, in Fig. 12, that the inside temperature mean value have a similar behaviour with the one at the outside of the structure. However, by comparing with the external $\mathrm{T}$ (Text) conditions applied we can note a phase displacement of about $2 \mathrm{~h}$ in time between the inner $\mathrm{T}$ (Tint) and Text essentially depending on the nature of the walls of the structure.

By comparing with Figs. 6a this point confirms the results obtained with $\varphi=0 \mathrm{~h}$ on the role of the walls.

By doing a direct comparison between the figs. 12 and $6 \mathrm{a}$ it appears clearly that for each case (wet or dry bottom wall) the very similar main behaviour of the air exchanges is only slightly modified, in the first rising part of the curve, by the presence of the inside thin layer of wet air. Consequently, the "thermal driving force" resulting from the temperature difference between outside and inside air leading to these exchanges seems to be confirmed. It participates in the renewing and possibilities of condensation of the more or less high quantity of humid air penetrating inside the considered structure.

For the wet bottom case, a direct comparison between the Figs. $12 \mathrm{~b}$ and $6 \mathrm{~b}(\varphi=0 \mathrm{~h})$ show a quasi-similarity in the duration and maximal amplitude of the mean quantity of the condensed water. However, the condensation process takes place clearly during the decreasing external temperature period in relation with the feeble air exchanges between outside and inside. In addition, there is another lower peak more important than in the phase $\varphi=0 \mathrm{~h}$ at the same time.

For the dry bottom case there is an important displacement of the main peak of condensed water which appears during the higher $\mathrm{RH}$ value. Its amplitude is of 2,5 times lower than for the wet bottom and its duration reduced. But, by comparison with the phase $\varphi=0 \mathrm{~h}$, its amplitude and duration are about 20 times higher.
These figs. 13 present an amazing difference with the results obtained of the phase $\varphi=0$ (fig. 7).

For the wet bottom case as for the dry one there is a stabilization in 3 days as previously observed.

For the phase $\varphi=12 \mathrm{~h}$, the yield is about twice lower with the wet bottom than with the dry one. It is not the case for phase $\varphi=0 \mathrm{~h}$ where it appears that we can reach $\sim 18 \%$ with the wet bottom when the dry one is quasi nil.

These results highlight the role of the phase in the water condensation process and lead and press on us to attempt to determine the optimal conditions to obtain the best results.

\section{Conclusion/prospects}

From a parallelepipedic structure, like the Arles-sur-Tech sarcophagus, we have attempted to determine the possibilities to harvest the water droplets obtained by the ambient air condensation with a view to solve the actual decrease of water supply. The oldest known written report dealing with the production of water in this sarcophagus is dated 1591 but there is not a lot of works giving satisfactory explanations for this water production of which $10 \%$ only would be due to condensation effects [16].

We have based our parallelepipedic structure on this sarcophagus example, of which the dimensions, the internal volume, the thickness and nature (marble) of the walls are fixed and the "slits between the lid and the body" [16] are represented by an orifice. Our structure, as the sarcophagus, is submitted to external temperature and hygrometry constraints.

Numerous parameters are to be considered as able to produce condensation of the water vapour inside this parallelepipedic structure.

Among this lot of efficient parameters, we have attempted to determine, the more important. Our first boundary conditions choice were the external temperature and $\mathrm{RH}$ and the temporal phase $\varphi$ linking these two parameters.

In our previous paper [1], to simplify, we have considered that the inside bottom wall was remaining dry all along the 
computation. In these conditions, the results obtained have pointed out an important dependency of the water vapour quantities as a function of the considered parameters and principally the phase.

In this study, the new parameter taken in consideration is the possibility to have a remaining high constant thin wet water vapour layer on the inside bottom wall, named "dead volume" in [16].

We have compared the various curves obtained in the case of an inside wet bottom wall and the same bottom wall assumed remaining dry [1], for the width section only and for the two phases, $\varphi=0$ and $\varphi=12 \mathrm{~h}$. It results that the external-internal temperature gap, depending on the nature and thickness of the walls, acts similarly, for the two phases, as a "thermal driving force" on the exchanges between outside and inside air through the orifice and on the internal air circulation. By this air renewing, the external water vapour can be introduced inside the structure and, depending on the external $\mathrm{RH}$ and the phase $(\mathrm{T} / \mathrm{RH})$, conditions for water vapour condensation can be reached.

As we have previously determined, ([1], fig. 13), we have now confirmed, by testing the possibility of the presence of a thin wet water vapour layer on the inside bottom wall, that one of the more significant parameter is the phase linking temperature and hygrometry and that the condensed water vapour quantities are very depending on this phase $\varphi(\mathrm{T} / \mathrm{RH})$. It appears possible to reach a maximal value when $\varphi$ (maximal $\mathrm{RH}$ value) would be between 9 and $18 \mathrm{~h}(6 \mathrm{pm})$.

This point needs to be confirmed.

Taking into consideration an inside bottom wall covered by a thin layer of water vapour remaining at a constant level has now permitted to show the role of this new parameter:

- for phase $\varphi=0$, it acts as a "starter" and a "feed-back" in the condensation process inside the considered structure enhancing importantly the mean condensed water quantity,

- for phase $\varphi=12 \mathrm{~h}$, it is not so evident due to an apparent reduced yield.

The systematic study of the influence of all these parameters and the results already obtained open some new prospects in understanding the condensation phenomena inside this type of structure with a view to enhance it.

The actual running computations using other conditions as nature and thickness of the walls, length section and variable orifice size, acting on the residence time and renewing of the water vapour inside the volume, equally show the existence of condensed water vapour maximal values depending on the fixed conditions $[14,15]$.
Acknowledgements We thank Mr. Stéphane Glockner of the TREFLE Laboratory - UMR 8508, 16, av. Pey-Berland, 33607 Pessac (France) Cedex, for his assistance in using the finite volumes method.

\section{Compliance with ethical standards}

Conflicts of interest On behalf of all authors, the corresponding author states that there is no conflict of interest.

Publisher's Note Springer Nature remains neutral with regard to jurisdictional claims in published maps and institutional affiliations.

\section{References}

1. Batina J, Peyrous R (2013) Simulation of water vapour condensation in a partly closed structure: influence of the external conditions of temperature and humidity. ISRN Atmospheric Sci 2013:1-11

2. Wahlgren RV (2001) Atmospheric water vapour processor designs for potable water production: a review. Water Res 35(1):1-22

3. Nikolayev VS, Beysens D, Gioda A, Milimouk I, Katiushin E, Morel J-P (1996) Water recovery from dew. J Hydrol 182:19-35

4. Muselli M, Beysens D, Marcillat J, Milimouk I, Nilsson T, Louche A (2002) Dew water collector for potable water in Ajaccio (Corsica Island France). Atmospheric Res 64(N+1-4):297-312

5. Beysens D, Milimouk I, Nikolayev V, Muselli M, Marcillat J (2003) Using radiative cooling to condense atmospheric vapour: a study to improve water yield. J Hydrol 276:1-11

6. Beysens D, Muselli M, Milimouk I, Ohayon C, Berkowicz S, Soyeux E, Mileta M, Ortega P (2006) Application of passive radiative cooling for dew condensation. Energy 31:1967-1979

7. Beysens D., Milimouk I, Nikolayev V.S., et al., (2006), Comment on «the moisture from the air as water ressource in arid region: hopes, doubt and facts » by Kogan and Trahtman, J Arid Environ, vol $67, n^{\circ} 2,343-352$

8. Clus O, Ouazzani J, Muselli M, Nikolayev V, Sharan G, Beysens D (2006) Radiation-cooled dew water condensers studied by computational fluid dynamic (CFD). European PHOENICS user meeting, Wimbledon, London, UK

9. Imad Lekouch (2010) Production d'eau potable par condensation passive de l'humidité atmosphérique (rosée). Physique atmosphérique et Océanique. Université Pierre et Marie Curie, Paris VI; Université Ibn Zohr, Agadir (Maroc)", University Doctor Thesis (23/02/2010)

10. Gandhidasan P., Abualhamayel H.I., (2005), "Modeling and testing of a dew collection system ". Desalination, vol. 180, $\mathrm{n}^{\circ} 1-3,47-51$

11. Beysens D., Muselli M., Nikolayev V.S., Narhe R., Milimouk I, (2005), "Measurement and modeling of dew in island, coastal and alpine areas". Atmos Res, vol. 73, n¹-2, 1-22

12. Caltagirone J.-P. and Breil J., (1999), “A vector projection method for solving the Navier-stokes equation". Comptes Rendus de l'Académie des Sciences - Séries IIB-Mechanics-PhysicsAstronomy, Volume 327, $\mathrm{n}^{\circ}$ 11, 1179-1184

13. Ben Gido FE, Broday DM (2016) Assessment of atmospheric moisture harvesting by direct cooling. Atmos Res 182(2016):156-162

14. Batina J, Peyrous R, Castaing-Lasvignottes J (2008) Condensation de vapeur d'eau en milieu partiellement clos soumis à des conditions périodiques de température et d'humidité. Proc SFT (French Society of Thermics) Congress 2008, Toulouse (France) I:345-350

15. Batina J, Peyrous R, Castaing-Lasvignottes J (2009) Conditions opératoires optimales favorisant la condensation de vapeur d'eau en milieu partiellemnt clos. Proc JITH (International days in Thermics) Congress 2009, Djerba (Tunisie)(83): 345-350 
16. Beysens D, Muselli M, Ferrari J-P, Junca A (2001) Water production in an ancient sarcophagus at Arles-Sur-tech (France). Atmos Res 57:201-212

17. Perard G, Leborgne C (1961) Sarcophage d'Arles-Sur-tech, technical report. Houille Blanche 6:873-881
18. Delage Santacreu S (2006) Méthode de raffinement de maillage adaptatif hybride pour le suivi des fronts dans les écoulements incompressibles. Thesis, University of Bordeaux I (France)

19. Devres Y.O., (1994), "Psychrometric properties of humid air: calculation procedures". Appl Energy, Volume 48, n 1, 1-18 